\title{
Water adsorption in MOFs: fundamentals and applications
}

\author{
Jérôme Canivet ${ }^{a}$ Alexandra Fateeva, ${ }^{b}$ Youmin Guo,${ }^{a}$ Benoit Coasne ${ }^{c, d}$ and David \\ Farrusseng ${ }^{*} a$
}

This critical review presents the fundamental and practical aspects of water adsorption in MetalOrganic Frameworks (MOFs). The state of the art of MOF stability in water, a crucial issue to many applications in which MOFs are promising candidates, is discussed here. Both the stability in gaseous (such as humid gases) and aqueous media are considered. By considering a non exhaustive yet representative set of MOFs, the different mechanisms of water adsorption in this class of materials are presented: reversible and continuous pore filling, irreversible and discontinuous pore filling through capillary condensation, and irreversibility arising from the flexibility and possible structural modifications of the host material. Water adsorption properties of more than 60 MOF samples are reported. The applications of MOFs as materials for heatpumps and adsorbent-based chillers and proton conductors are also reviewed. Some directions for future work are suggested as concluding remarks.

\section{Introduction}

Water is everywhere! The design and development of moisturestable porous materials is crucial for industrial applications such as gas storage and separation, sensing, catalysis, and proton conduction. Unfortunately, the first discovered porous metalorganic frameworks MOF- $5^{1}$ and HKUST-1, ${ }^{2}$ which have strongly contributed to the boost of the MOF domain, turned to be particularly moisture sensitive. ${ }^{3-5}$ Despite the great interest stirred by their extraordinary specific surface and calibrated pore size, the degradation in the atmosphere of these materials has obviously limited interests for industrial applications. On the other hand, solubility properties of MOFs are especially attractive for in vivo medical applications. Water-unstable MOFs called Bio-MOFs (such as Fe-nicotinate BioMIL-1) were designed and developed "on purpose" as drug carriers under physiological conditions 6,7 and for imaging. ${ }^{8-10}$ The understanding of the degradation mechanisms in the presence of water, either in vapour or liquid phases, is hence of utmost importance for the design and development of the next generations of porous coordination polymers with appropriate water sensivity or insensivity in the context of real applications. The first chapter of this review deals with the stability of MOFs in humid atmospheres and in aqueous media, and presents the different degradation-dissolution mechanisms.

The control of water adsorption in microporous solids is crucial for the development of industrial processes. For instance, the temperature required for the regeneration of adsorption or chromatography columns made up of molecular sieves is governed by their water adsorption properties. On the other hand, hyperhydrophobic zeolites can be applied for molecular springs upon water intrusion. ${ }^{11,} 12$ Of particular importance for environmental applications, water adsorption is often detrimental for $\mathrm{CO}_{2}$ capture using hydrophilic materials since water acts as a strong competitor. ${ }^{13}$ Nevertheless, it was demonstrated that controlled water adsorption can enhance $\mathrm{CO}_{2}$ capture in MOFs ${ }^{14-16}$ such as MOF-100, ${ }^{17}$ HKUST- $1,{ }^{18}$ MIL$101^{19}$ and MIL-53. ${ }^{20}$ The inventory of water effects on diverse applications is vast and complex, and goes therefore well beyond this review. We have chosen to focus this review on two applications where water adsorption properties are directly involved in the performance of the MOF. The application of MOF as materials for (1) heat-pumps and adsorbent-based chillers and (2) proton conductors is described in the third chapter with emphasis, where possible, on the relationship between structure and water adsorption. Other applications for which water adsorption in MOF is relevant include dehumidification, ${ }^{21}$ water purification, ${ }^{22,23}$ thermal batteries, and production and delivery of drinking water in remote areas (for a very recent study on these applications, see Ref. ${ }^{24}$ ).

Kaskel and co-workers first reported that water adsorptiondesorption isotherms on a series of diverse MOFs display a broad variety of behaviours from hyperhydrophobic for ZIF-8 to exceptional water capacity for MIL-100/-101. ${ }^{25}$ The diversity of water adsorption properties of MOFs is regularly confirmed with novel MOFs. The effects of pore size and surface functionalization by organic groups have been thoroughly investigated in the case of $\mathrm{H}_{2}, \mathrm{CH}_{4}$, and $\mathrm{CO}_{2}$ adsorption. ${ }^{26-29} \mathrm{~A}$ few rules of thumb have been established and predictive models have been developed to guide the rational design of MOFs. In contrast, less effort has been devoted to unravel the diverse mechanisms of water adsorption in MOFs. The effects of pore size, pore morphology, and flexibility on water adsorption have not been investigated in a systematic fashion. The lack of comprehensive and predictive models of water adsorption is obviously limiting the design of MOFs for applications where water is present or directly involved. The second chapter of this review provides a description of the different adsorption mechanisms that occur in MOFs. Then, a comprehensive review of the literature is illustrated with specific examples. 


\section{Stability of MOF in the presence of water}

Beyond the observation of MOF degradation in the presence of water by means of powder X-ray diffraction (PXRD) and nitrogen adsorption, the rational design of water-stable materials implies the study of the complex behaviour of MOFs upon water exposure. Both the effects of exposure to humid vapours (like in flue gases) and aqueous phases must be considered.

\subsection{Stability in pure water}

STABILITY IN WATER VAPOURS. In a seminal study Low and co-workers studied by X-Ray Diffraction (PXRD) the stability of a series of ten MOFs having different organic linker, pore structure, metal node nature and coordination, and monitored their stability after exposure to $1 \mathrm{~mol} \%$ steam for few hours. ${ }^{30}$ The energy assessed using molecular modelling of the ligand displacement by water molecule was compared with experimental results for each MOF to map their steam stability (Fig. 1). Through such a combined virtual and experimental screening, these authors investigated how the framework nature (metal coordination, ligand composition) and dimensionality govern the relative stabilities of MOFs in water. They concluded on the importance of metal-ligand bond strength as a key criterion of the water-stability of the materials, more important than the metal geometry or valence in the case of MOFs containing trivalent metallic cations. In their study, the most stable materials were MIL-110/-101, CPO-27 (also known as MOF-74) and ZIF-8. It is noteworthy that this study did not take into account the kinetics of the water-induced framework decomposition since the molecular modeling strategy was based on the equilibrium ground and transition state configurations (thermodynamics). While such stability studies are very useful, it should be emphasized that contradicting results are sometimes reported in the literature. For instance, while HKUST-1 was found to be highly stable in water vapour in Ref. ${ }^{28}$, other authors have observed significant decrease in their specific surface area or water capacity after water adsorption. ${ }^{25,31}$

More recently, the stability of a series of six MOFs was estimated after water adsorption measurement under $80 \%$ Relative Humidity $(\mathrm{RH})$ at room temperature. ${ }^{5}$ The surface area loss estimated from nitrogen adsorption at $77 \mathrm{~K}$ was used to rank the solid stability after humidity exposure. On the time of the experiment, the stability follows the order: $\mathrm{UiO}-66-\mathrm{NH}_{2}>\mathrm{CPO}-$ 27, HKUST-1 >> DMOF-1, UMCM-1. The crystal structures were reported to be preserved for almost all the samples, except for DMOF-1 and UMCM-1 whose instability was attributed to the low coordination of tetracoordinated zinc-carboxylate cluster nodes. Although $\mathrm{Zr}-\mathrm{MOF}$ such as UiO-66 were found to be extremely stable in the presence of water, isostructural UiO-67, MOF-805 and MOF-806 made from biphenyldicarboxylate or bipyridinedicarboxylate ligands (instead of benzenedicarboxylate in UiO-66) are unstable in water vapor. ${ }^{24}$, 32 The instability of the extended biaryl-based Zr-MOF derivatives was attributed to the torsional strain undergone by the crystal leading to its structural collapse. Similar adsorption isotherms found for Al-MIL-100 seem to indicate instability or at least partial collapse of the structure. ${ }^{24}$ Using PXRD, Dietzel and co-workers pointed out that exposure to oxygen from ambient air during water desorption/adsorption initiates the degradation of $\mathrm{Ni} / \mathrm{Mg}-\mathrm{CPO}-27 .{ }^{33}$

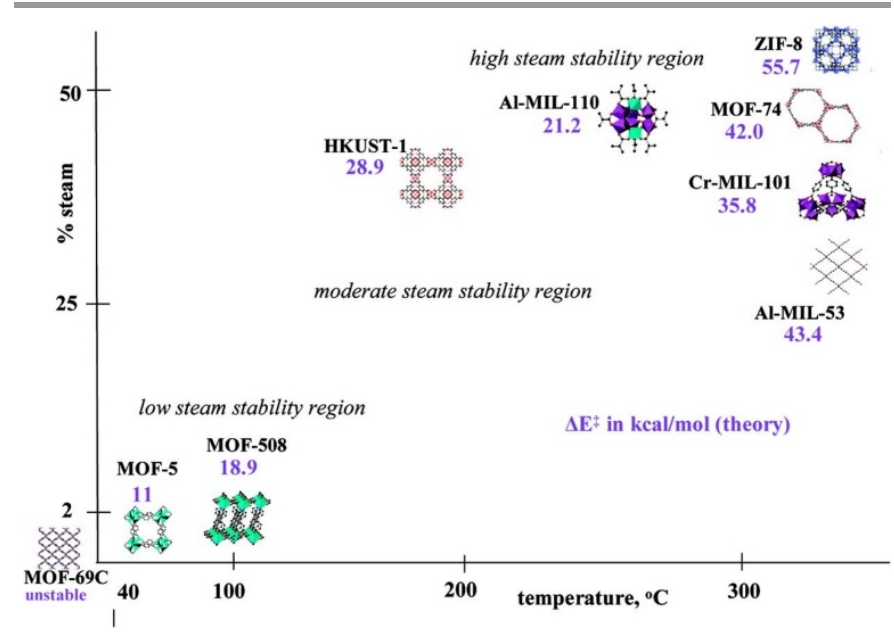

Fig. 1 Steam stability map of MOFs. The position of the structure for a given MOF represents its maximum structural stability as probed by XRD measurement, while the energy of activation for ligand displacement by a water molecule as determined by molecular modeling is represented by the magenta numbers (in $\mathrm{kcal} / \mathrm{mol}$ ). Reprinted with permission from ref. ${ }^{30}$.

STABILITY IN LIQUID WATER. The stability of various MOFs immersed in pure water or in wet dimethylformamide (DMF) has been investigated by Matzger and co-workers on timescales from hours to months. ${ }^{34}$ The stability was assessed according to PXRD recorded before and after exposure at room temperature. The zinc carboxylates MOF-5 and MOF-177 were found to be unstable in water:DMF mixtures with ratios higher than 1:4. MOF-5, which is composed of $\mathrm{Zn}_{4} \mathrm{O}(\mathrm{COO})_{6}$ secondary building units (SBUs), is indeed known to be unstable under exposure to water vapor ${ }^{4}$ or liquid water. ${ }^{3}$ The stability of MOF-5 under different relative humidities was also demonstrated in a study on sampling formaldehyde from air. ${ }^{35}$ The kinetics of MOF-5 synthesis in diethylformamide (DEF) in the presence of water was studied by Mertens and co-workers. ${ }^{36}$ Hydrated zinc nitrate acts as a buffer and stabilizes the $\mathrm{pH}$ ensuring slow acid deprotonation and leading to fairly constant precipitation rate and well-ordered crystals. The study shows that MOF-5 is obtained as an intermediate solid which is transformed to thermodynamically favourable MOF-69C. The latter is built from inorganic $\mathrm{Zn}_{3}(\mathrm{OH})_{2}(\mathrm{COO})_{4}$ monodimensional infinite chains. In a systematic study, a stability phase diagram in diethylformamide was proposed as a function of temperature and water concentration. This phase diagram shows that the stability domain of MOF-5 is restricted to low water concentration (Fig. 2). 


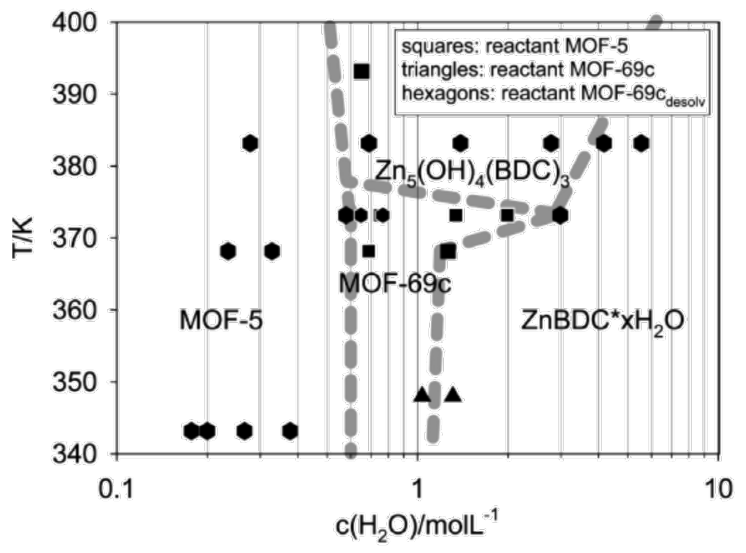

Fig. 2 Phase diagram mapping the stability of zinc carboxylate SBUs in various water-DEF mixtures. Reprinted with permission from ref. ${ }^{36}$.

Allendorf and Greathouse reported Molecular Dynamics simulations which show that distortion in the MOF-5 lattice structure already occurs at low water content. Complete collapse occurs at higher water loading through the replacement of the ligand oxygen atoms by water oxygen atoms in the $\mathrm{Zn}$ coordination sphere. ${ }^{37}$ Matzger and co-workers also showed that UMCM-150 is stable in water:DMF ratio 9:2 for hours and also for months with a lower amount of water (water:DMF $=3: 40$ ). ${ }^{34}$ In contrast, copper paddlewheel MOFs such as MOF-505 and HKUST-1 were found to be stable for months in aqueous solvent (water:DMF = 5:1). However, HKUST-1 starts to decompose in pure water after 24 hours. Finally the chromium carboxylate MIL-100 and zinc imidazolate ZIF-8 were stable for months in pure water. In line with this last result, PXRD showed that imidazolate MOFs such as ZIF-8 or SIM-1 are stable after treatment in boiling water for at least 24 hours. ${ }^{38,39}$ Bellat and co-workers showed that Al-MIL-53 undergoes degradation in boiling water to form core-shell structures. ${ }^{40}$ The surface of MIL53 crystals is transformed into gamma alumina under these conditions while ligands are intercalated into the MOF pores.

\subsection{Stability in aqueous acid/base}

While some MOFs such as Zr-porphyrin PCN-222, 224, and 225 are stable in some extreme aqueous conditions, ${ }^{41-43}$ it is generally acknowledged that most MOFs formed by carboxylates or imidazolates dissolve in acidic media, either aqueous hydrochloric or hydrofluoric acid solution. ${ }^{44}$ This is due to the protonation of their organic linker in such media. MOF stability in strong alkaline solutions have been evaluated for a few materials. In an early study, Yaghi and co-workers reported that the PXRD pattern of ZIF-8 remains unchanged after 24 hours in an 0.1 and $8 \mathrm{M}$ aqueous sodium hydroxide solution at $100^{\circ} \mathrm{C} .^{39}$ These authors concluded that the hydrothermal stability of ZIF8 is superior to those of original MCM and SBA mesoporous silica, even competing with the ultrastable derivatives of these materials. However, hydrolysis under hydrothermal conditions of the same materials was reported elsewhere. ${ }^{45}$ Other studies have reported that strong aqueous bases such as $\mathrm{KOH}$ or $\mathrm{NaOH}$ dissolve the structure of UiO-66 and UiO-66- $\mathrm{NH}_{2}{ }^{46}$ as well as that Al-MIL-53. ${ }^{40}$

On the other hand, materials such as BioMOFs, which are designed for medical applications, were studied in simulated physiological media. Serre and co-workers ranked the stability of a series of seven carboxylate-based MOFs in a phosphate buffer aqueous solution at $\mathrm{pH}=7.4$ and $37^{\circ} \mathrm{C} .{ }^{47}$ The stability follows the order Fe-MIL-100/-127 $>$ Fe-MIL-53, UiO-66- $\mathrm{NH}_{2}$ $>$ Fe-MIL-53-Br $>>$ UiO-66 $>$ UiO-66-Br. This series shows that the stability of the UiO series is related to the donor effect of the ligand substituent as indicated by the Hammet constant (the most electron rich being the most stable). ${ }^{48}$ The ligand release is facilitated by its displacement by phosphates from the buffer solution and the formation of metal oxide. Indeed a higher stability of the tested MOFs was found in pure water than in phosphate buffer.

Beyond simple degradation or collapse of the framework structure, the stability of MOF can be related to an assemblydisassembly equilibrium. Cohen and co-workers studied the ability of MOFs to exchange ligands as well as metal cations in water suspension. ${ }^{49,50}$ As an example, when the UiO-66 solid made from 1,4 benzenedicarboxylic acid is suspended in an aqueous solution containing the substituted linker 2-amino-1,4 benzenedicarboxylic acid, the latter is introduced in the solid by an exchange process yielding to an isoreticular $\mathrm{UiO}$ solid containing both linkers. Although the mechanism of ligand exchange has not been investigated in depth, it is obvious that the solubility difference of the linkers is an important driving force of the process. Similarly, isoreticular MIL-68-( $\left.\mathrm{Br} / \mathrm{NH}_{2}\right)$ solids were obtained. ${ }^{51}$ The authors have extended this principle to cation exchange to Al-MIL-53 with an aqueous solution of $\mathrm{Fe}^{3+}$ leading to (Fe/Al)-MIL-53. ${ }^{49}$

\subsection{Structure-Stability relationships}

Metal-LIGAND BOND. The stability of MOFs in water can be attributed to both the electronic and steric effects of the ligand on the metal node. Indeed, the strength of Metal-Oxygen/MetalNitrogen bonds, ${ }^{30}$ combined with the shielding ability of the ligand to protect the inorganic node against water coordination, drive the water resistance of the materials. As demonstrated for pyrazolate $^{52}$ and imidazolate, ${ }^{39}$ the stability of the framework formed by its coordination to a cation increases upon increasing the $\mathrm{pKa}$ of the ligand; the metal ligand bond is stronger when very acidic metals or very basic ligands are used. This property explains why MOFs made up of strong Lewis acids (Al(III), $\mathrm{Cr}(\mathrm{III}))$ and/or azolates $(\mathrm{pKa}=14$ vs carboxylate $\mathrm{pKa}=3.5)$ are the most stable such as Al-MIL-53, Cr-MIL-101 and ZIF-8 (Fig. 1). ${ }^{30}$

In addition to thermodynamics, kinetics plays an important role in the degradation of MOF through hydrolysis. Moreover, hydrophobic ligands such as methylated linkers improve the stability of the structure on a short time scale only (the position of the substituents being crucial). Indeed, for DMOF series, the fully tetramethylated terephthalate ligand allows the framework to be stable upon water adsorption. ${ }^{53,54}$ Given the fact that high 
water uptakes are observed in this case, the stability cannot be attributed to water exclusion but to the shielding of $\mathrm{C}(\mathrm{O})-\mathrm{O}$ and $\mathrm{Zn}$ clusters surrounded by the numerous methyl groups which make the node hardly accessible to water. Similar conclusions were reported for MOF-508 having Me-bipy pillars, ${ }^{55}$ Banasorb22 with trifluoromethoxy groups, ${ }^{56}$ and frameworks made up of phosphonate linkers. ${ }^{57}$

In addition to the ligand structure, the metal coordination in the framework nodes was found to govern the water stability of MOF structures. IRMOF-1-type structures with the three metals $\mathrm{Zn}, \mathrm{Mg}$, and Be were studied using Born-Oppenheimer Molecular Dynamics in order to determine their behaviour in liquid water. ${ }^{58}$ The fully hydrated Be based compounds were found to be more stable than their analogues containing $\mathrm{Mg}$ or $\mathrm{Zn}$. The reason given by the authors to explain the relative instability of $\mathrm{Mg}$ and $\mathrm{Zn}$-based MOFs compared to the $\mathrm{Be}$ analogues is the tendency of the metal to form penta- and hexacoordination spheres combined with the flexibility of the $\mathrm{M}_{4} \mathrm{O}$ core and the weaker metal-oxide bonds. Furthermore, $\mathrm{Mg}$ structures were found to break differently from the $\mathrm{Zn}$ analogues due to the larger rigidity of their core and the strong $\mathrm{Mg}-\mathrm{O}$ coordination. This would prevent further water coordination to the metal, in contrast to $\mathrm{Zn}$-IRMOF-1 in which $\mathrm{Zn}$ clusters are more flexible and open up more easily. Moreover, these authors also pointed out that kinetic effects were behind the hydrothermal resistance of Be-IRMOF-1 structures; the activation energy for the metal-ligand dissociation leading to the hydrated Be-terephthalate compound from Be-IRMOF-1 is indeed very steep. Similarly, in the case of UiO-type ${ }^{5,59}$ and MIL-100/-101 MOFs, ${ }^{60,61}$ the high stability of these materials was related to the high coordination of the metal centres. Indeed, upon water adsorption up to $90 \% \mathrm{RH}$, the 8 -coordinated zirconium-based UiO-66 was the only one to retain both its crystallinity and porosity compared to Mg-MOF-74, DMOF-1, HKUST-1, and UMCM- $1 .^{5}$

The nature of the metal ion itself also plays a crucial role in the stability of MOFs in water, as demonstrated by Jhung and coworkers for isotopic MIL-53/-47 frameworks. ${ }^{62}$ Based on both the BET surface area and PXRD analysis, these authors ranked the stability of these materials after exposure to $7 \times 10^{-2} \mathrm{M} \mathrm{NaOH}$, $7 \times 10^{-2} \mathrm{M} \mathrm{HCl}$ aqueous solutions at room temperature and pure water at $80^{\circ} \mathrm{C}$ : Cr-MIL-53 > Al-MIL-53 > V-MIL-47. These authors did not attribute the relative stability of the framework to the metal-ligand bond strength (the $\mathrm{M}-\mathrm{O}$ bond energy follows the order $\mathrm{V}>\mathrm{Al}>\mathrm{Cr}$ ). Moreover, the relative stability cannot be attributed either to the metal oxidation state or to the coordination geometry which are the same for the three metal cations. These authors have proposed a ranking according to the inertness (i.e., low lability) of the metal cation.

By comparing cations in isoreticular series of MOF, Chabal and co-workers described the behaviour of $\mathrm{M}_{2}$ (bdc) 2 (dabco) series containing either $\mathrm{Cu}, \mathrm{Zn}$, Co or $\mathrm{Ni}$ cations under humid conditions. ${ }^{63}$ The water-induced degradation mechanism was reported to be different depending on the cation involved. According to density functional calculations combined with experimental water vapor adsorption, the $\mathrm{Cu}-\mathrm{O}$ bonds were found to undergo hydrolysis to form hydroxide species while the ligand displacement occurs to break $\mathrm{Zn} / \mathrm{Co}-\mathrm{O}$ bonds. Finally, under the conditions described above, the Ni-dabco MOF shows a very low reactivity i.e. high stability in the presence of water.

DEGRADATION MECHANISMS. Low and co-workers reported two main degradation mechanisms of MOFs exposed to water: (1) ligand displacement and (2) hydrolysis. Both mechanisms were established from computational chemistry and confirmed experimentally. ${ }^{30}$ The ligand displacement reaction involves the insertion of a water molecule into the $\mathrm{M}-\mathrm{O}$ metal-ligand bond of the framework. This leads to the formation of a hydrated cation and to the release of a free ligand:

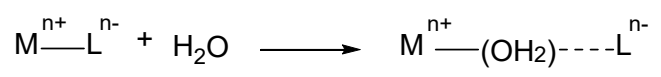

In contrast, during the hydrolysis reaction, the metal-ligand bond is broken and water dissociates to form a hydroxylated cation and a free protonated ligand:

$$
\mathrm{M}^{\mathrm{n+}} \mathrm{L}^{\mathrm{n}-}+\mathrm{H}_{2} \mathrm{O} \longrightarrow \mathrm{M}^{\mathrm{n}+}-(\mathrm{OH})^{-}+\mathrm{HL}^{(\mathrm{n}-1)-}
$$

A ligand displacement mechanism was proposed to explain the structural breakdown of ZrMOFs (UiO-66) in the presence of either sodium hydroxide or water (Fig. 3). ${ }^{32}$

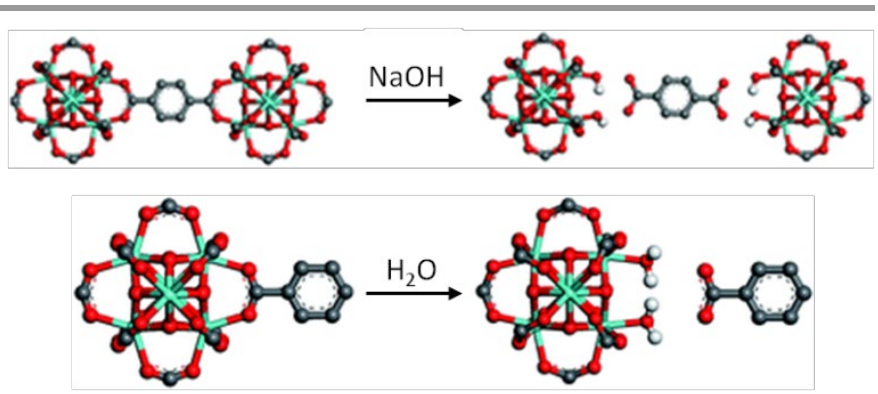

Fig. 3 Ligand displacement mechanism proposed to explain the breakdown of UiO66 in the presence of sodium hydroxide or water. Reprinted with permission from ref. ${ }^{32}$.

Using first-principles calculations with various water loadings, the ligand displacement was also proposed as the main mechanism for the framework decomposition of hydrophobic IRMOF ${ }^{64}$ It was found that, in addition to the water molecule involved in the ligand displacement, additional water stabilizes both the hydrated metal species and the ligand being displaced. Furthermore, Coudert and co-workers reported that $\mathrm{ZnO}$ clusters act as hydrophilic defects in hydrophobic MOFs. They demonstrated that, at high water loading, the metal oxide cluster stabilizes a water cluster in its neighbourhood which promotes the ligand displacement (see also Ref. ${ }^{65}$ for a theoretical discussion on the stability of MOFs in water). Such a mechanism may explain the presence of $\mathrm{Zn}-\mathrm{OH}$ defects which are active in acid catalysis. ${ }^{66,67}$

In addition to the thermodynamic stability of the framework, which is generally attributed to the M-O bond strength as mentioned above, more complex parameters are required to evaluate the kinetic stability of MOFs. Walton and co-workers 
reported that the breakdown of functional DMOF upon exposure to water is governed by kinetics. ${ }^{54}$ Both their experimental and computational studies show no direct correlation between the stability of a series of very water sensitive DMOFs and the basicity of their ligands. The water resistance of such frameworks depends thus on the activation energy barrier for the corresponding hydrolysis reaction. Similar conclusions were reported by Bellarosa et al. for (Be) IRMOF-1 framework. ${ }^{58}$

The prediction of water stability from the MOF composition and structure remains qualitative. Major trends in MOF stability versus water are acknowledged, even if some data available in the literature are somewhat contradictory. These discrepancies may find their origin in the different methods used to assess the stability of the frameworks. The assessment of crystallinity of a sample after moisture exposure or hydrothermal treatment may be misleading since crystallinity might be retained while a part of the solid is dissolved. ${ }^{68}$ The measurements of BET surface area and porous volume from $\mathrm{N}_{2}$ adsorption isotherms after exposure may also be misleading for the same reasons. On the other hand, cycling water adsorption isotherms is more appropriate for the evaluation of the stability under moisture exposure. Typically, if the desorption branch in such water adsorption isotherms crosses the adsorption branch, such as in the case of DUT-4, it can be concluded that the porous framework has collapsed totally or partially. ${ }^{25}$ The limitations of such a technique are that the origin of the degradation cannot be determined (amorphisation, hydrolysis, or other). Moreover, these measurements at high water pressure (higher than $\mathrm{P}_{\text {sat }}$ at $70^{\circ} \mathrm{C}$ ), which are relevant for hydrothermal processes, are difficult to perform. In addition to probing structural stability, water adsorption-desorption isotherms provide an appropriate mean for the characterisation of hydrophilic-hydrophobic properties of the porous solids. ${ }^{69}$

\section{Water adsorption-desorption in MOF}

\subsection{Adsorption-desorption mechanisms}

There are three main types of water adsorption mechanism: (i) adsorption on metallic clusters which modifies the first coordination sphere of the metal ion (chemisorption), (ii) layer/cluster (reversible) adsorption, and (iii) capillary condensation (irreversible). We illustrate below these mechanisms using three well-known case studies: microporous CPO-27 (also known as MOF-74), UiO-66, and mesoporous MIL-101. Comparison with water adsorption mechanisms in porous silica and carbons is also made.

The crystal structure of CPO-27 resembles a honeycomb and can be obtained with $\mathrm{Ni}^{2+}, \mathrm{Mg}^{2+}, \mathrm{Co}^{2+}, \mathrm{Zn}^{2+}$ as metal ions. The intersections of the honeycomb are formed by one-dimensional helical chains of cis-edge-connected metal-oxygen coordination octahedra. The channels have an accessible diameter of approximately $1.1 \mathrm{~nm}$. In its solvated state, the metal atom is coordinated by a single water molecule while the remaining coordination sites are occupied by oxygen atoms belonging to the organic linker. Upon heating, the solvating water molecule is desorbed which leads to a coordinatively unsaturated metal site (referred to as "cus") in the dehydrated structure. Such a dehydration step corresponds to a transformation of an octahedral six-coordinated into a five-coordinated species in a square-pyramidal geometry. An illustration of the electron wavefunction calculated by means of Density Functional Theory (DFT) shows the large unoccupied orbital in dehydrated $\mathrm{Mg}$ CPO-27 (Fig. 4). ${ }^{70}$

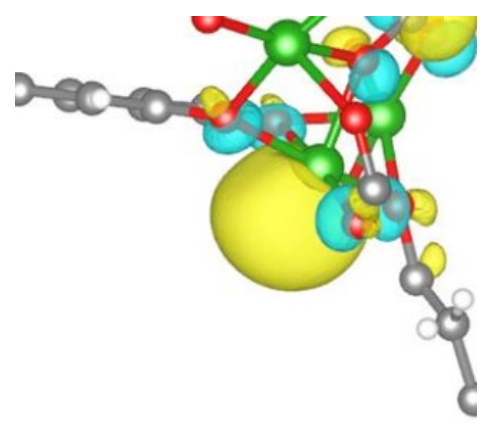

Fig. 4 Excited state wave function calculated by means of DFT for Mg-CPO-27. Mg atoms are shown in green, oxygen atoms in red, carbon atoms in gray, and hydrogen atoms in white. The two phases of the wave function are shown in yellow and teal. Reprinted with permission from ref. ${ }^{70}$.

The thermodiffractogram of $\mathrm{Zn}-\mathrm{CPO}-27$ contains abrupt changes which reveal structure deformation of the cluster upon dehydration. However, the porous topology remains identical and, for all metal ions, a structure analogous to the dehydrated CPO-27 is recovered once all the water molecules leave the compound. The density probability of water was determined using single crystal X-ray diffraction at room temperature on a hydrated sample (Fig. 5). ${ }^{71}$ The thermal displacement ellipsoids drawn at a $50 \%$ probability level shows that the density gets more localized as the water molecules become closer to the metal sites. On the other hand, in the centre of the cavity, the water molecules are delocalized which reflects the weaker adsorption energy far from the adsorption sites.

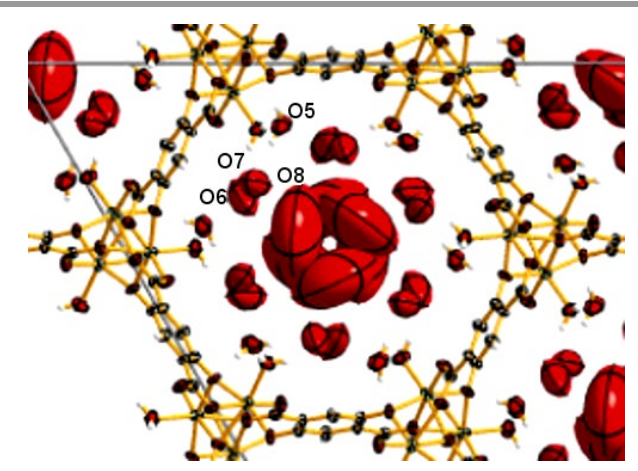

Fig. 5 Single crystal X-ray structure of CPO-27-Zn at room temperature with atom labelling. The ellipsoids correspond to thermal displacement of water molecule with an occupancy probability equal to $50 \%$. The size of the ellipsoids indicate the mobility of water molecules. Reprinted with permission from ref. ${ }^{71}$.

The adsorption strength of the water molecules were also visualized from structure refinement of diffraction data obtained upon controlled dehydration (Fig. 6)..$^{71}$ At $100^{\circ} \mathrm{C}$, the weakly adsorbed water molecules in the cavity centre desorb while water 
in the vicinity of the metal cluster remains adsorbed. Upon further heating, the water molecules coordinated to the metal sites remain adsorbed at $108^{\circ} \mathrm{C}$ and are desorbed at higher temperature $\left(195^{\circ} \mathrm{C}\right)$.
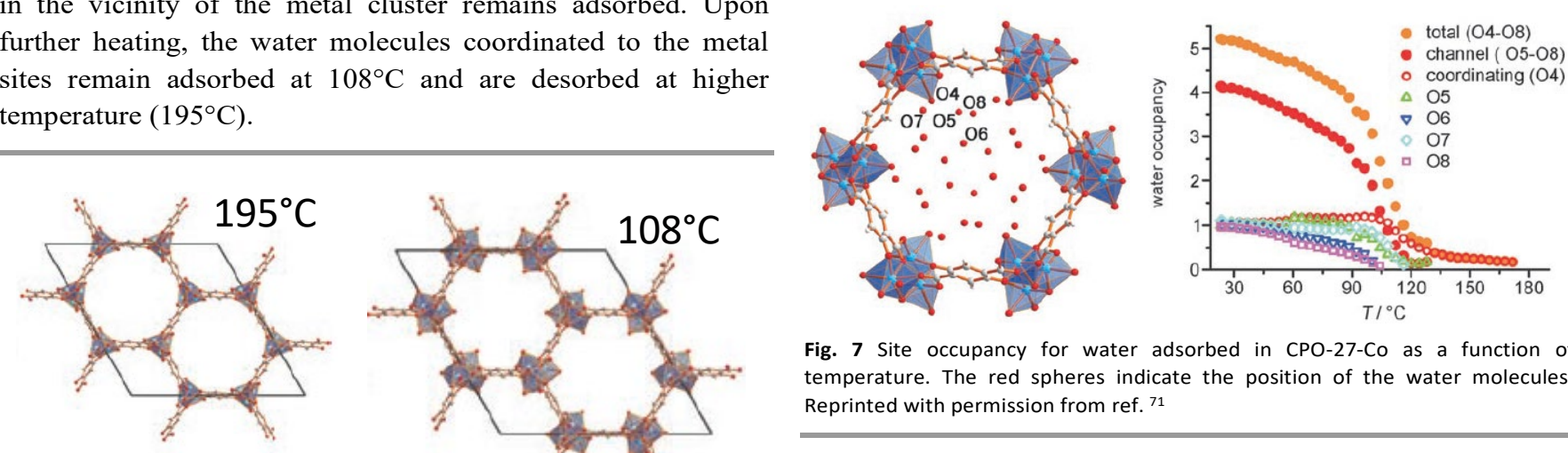

Fig. 7 Site occupancy for water adsorbed in CPO-27-Co as a function of temperature. The red spheres indicate the position of the water molecules. Reprinted with permission from ref. ${ }^{71}$
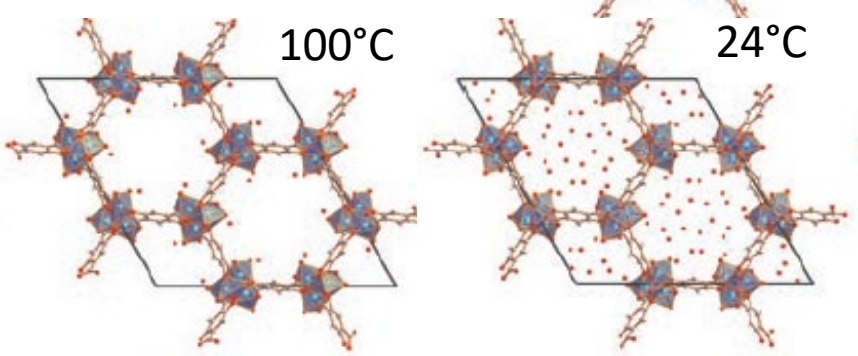

Fig. 6 Location of water molecules in CPO-27- $\mathrm{Zn}$ as a function of the temperature from powder X-ray analysis. The red spheres indicate the position of the water molecules. Reprinted with permission from ref. ${ }^{71}$.

Although the framework symmetry of Ni-CPO-27 does not change upon dehydration, in contrast to its $\mathrm{Zn}$ counterpart, local modifications occur which are revealed by substantial changes in its spectroscopic features. The removal of water from the cus modifies the optical spectrum of the host material. This result shows that the guest-host interaction between water and the MOF atoms induce changes in the local structure. ${ }^{72}$

Hydradation/dehydration in Co-CPO-27 proceeds in a similar fashion as in its Ni counterpart. Dehydration in Co-CPO27 was quantified by estimating water site occupancy from XRay thermodiffraction. ${ }^{71}$ Three main temperature desorption profiles were observed (Fig. 7). While the water molecules located in $\mathrm{O} 6$ and $\mathrm{O} 8$ (O6 is the closest molecule to the centre of the channel) have a site occupancy that first decreases upon heating, the two bulk water molecules in $\mathrm{O} 5$ and $\mathrm{O} 7$ leave the structure at a temperature of $90^{\circ} \mathrm{C}$. Above this temperature, their removal increases until all the bulk water disappears at $120^{\circ} \mathrm{C}$. The coordinating water molecule located in $\mathrm{O} 4$ remains unaffected until the temperature reaches $108^{\circ} \mathrm{C}$. At this temperature, more than three quarters of the bulk water molecules (O5, O6, O7, O9) have already desorbed from the channels. The water molecule in $\mathrm{O} 4$ starts to be removed from the structure and very little of it remains at $140{ }^{\circ} \mathrm{C}$. Dehydration is complete at $180^{\circ} \mathrm{C}$.
In summary, the strongest adsorption site in CPO-27 corresponds to the unsaturated metal site. Hydration/dehydration of water adsorbed in this site induces either local or global deformation of the framework. At a larger relative humidity (lower temperature), adsorption proceeds through reversible and continuous pore filling; strong adsorption sites (i.e. closest sites to the framework) get filled at low pressures followed by adsorption in sites corresponding to weaker adsorption energies. Strong and reversible adsorption of water molecules on unsaturated sites (cus), which are at the origin of the Lewis acidity of MOF, are usually found in dinuclear square paddlewheel systems such as HKUST-1 ${ }^{73}$ and in trigonal prism systems such as MIL-100 74,75 and MIL-101. ${ }^{76}$ The heat of adsorption of the first and second water molecules adsorbed on the dicopper paddle-wheel were estimated from dispersion-corrected DFT: $49 \mathrm{~kJ} / \mathrm{mol}$ and $-44 \mathrm{~kJ} / \mathrm{mol}$, respectively. These values are lower but comparable to the molar vaporization enthalpy of water ( $\sim 4$ $\mathrm{kJ} / \mathrm{mol}){ }^{77}$

Reversible hydration/dehydration of the Al-trimer in AlMIL-100 is accompanied by a change in the local symmetry as monitored by NMR investigations. ${ }^{74}$ Reversible hydration/ dehydration occurs at the inorganic cluster in UiO-66 but with a different mechanism than for the CPO family. The inorganic cluster of UiO-66 solids is a $\mathrm{Zr}_{6} \mathrm{O}_{4}(\mathrm{OH})_{4}$ octahedron, forming lattices with 12-fold connection through a 1,4-benzenedicarboxylate linker. ${ }^{59}$ Two $\mathrm{H}_{2} \mathrm{O}$ molecules per $\mathrm{Zr}_{6} \mathrm{O}_{4}(\mathrm{OH})_{4}$ cluster desorb from the structure when the material is heated above $250^{\circ} \mathrm{C}$. Such a dehydration step leads to a loss of one oxygen in the first coordination sphere of $\mathrm{Zr}$ atoms whose coordination decreases from 8 to 7 . Fig. 8 illustrates the fully reversible dehydroxylation process of $\mathrm{UiO}-66$, where each inorganic $\mathrm{Zr}_{6} \mathrm{O}_{4}(\mathrm{OH})_{4}$ cluster rearranges into a distorted $\mathrm{Zr}_{6} \mathrm{O}_{6}$ cluster showing a preferential squeezing direction. ${ }^{59,78,79}$ 

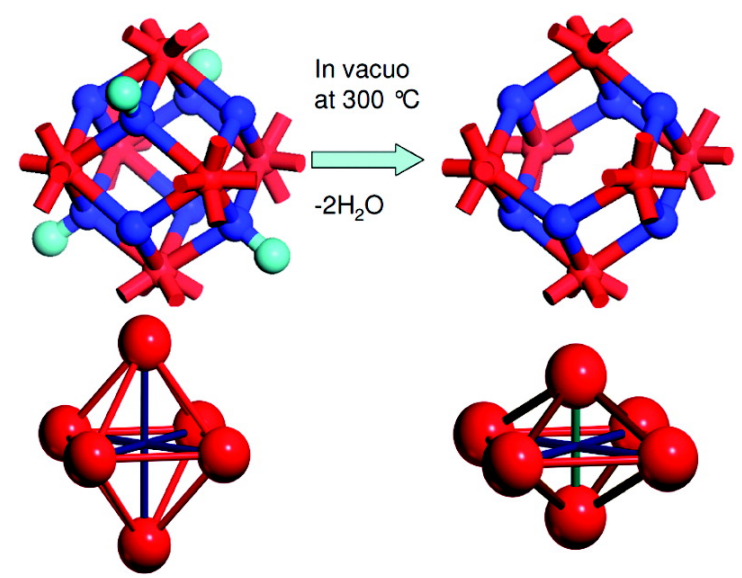

Fig. 8 (top) Stick and ball representation of dehydroxylation undergone by the inorganic $\mathrm{Zr}_{6} \mathrm{O}_{4}(\mathrm{OH})_{4}$ cluster upon thermal treatment at $300{ }^{\circ} \mathrm{C}$ in vacuo. This dehydration leads to a distorted $\mathrm{Zr}_{6} \mathrm{O}_{6}$ cluster. Red, blue, and cyan colors refer to $\mathrm{Zr}, \mathrm{O}$, and $\mathrm{H}$ atoms, respectively. (bottom) Stick and ball representation of the perfect $\mathrm{Zr}_{6}$ octahedron. Reprinted with permission from ref. ${ }^{78}$.

The mechanism of water physisorption has been studied for the isostructural UiO-66 made with fumarate linkers (also referred to as MOF-801). ${ }^{24,} 80$ Despite the minor difference in pore size of $\sim 0.1 \mathrm{~nm}$, it can be assumed that the mechanisms of water physisorption in native UiO-66 and MOF-801 are similar. As shown in Fig. 9, at low water pressure, the water molecules are adsorbed through $\mathrm{H}$-bonding in two tetrahedral cavities close to the $\mu_{3}-\mathrm{OH}$ groups of SBU (sites I and II). Upon increasing the pressure, more water molecules get confined in the cavity by forming new hydrogen bonds (site III) with several of the adsorbed molecules at the primary binding sites. Such further adsorption leads to the formation of water cubane clusters. Finally, these secondarily adsorbed molecules provide further binding sites to facilitate the adsorption in the larger cavities and subsequent water condensation in the framework. This physisorption mechanism seems somewhat similar to those found for activated porous carbons for which surface water molecules first adsorb onto oxygenated/hydroxylated surface sites. These adsorbed water molecules then act as nucleation sites for the formation of larger water clusters. Eventually, these clusters connect either along the surface or across the pore, which leads to pore filling. ${ }^{81,82}$ When the density of oxygenated sites at the surface is appreciable, pore filling occurs through a continuous filling process. Such a continuous filling, which is observed for UiO-66 solids, is confirmed by the large heats of adsorption at low coverage. ${ }^{83,84}$
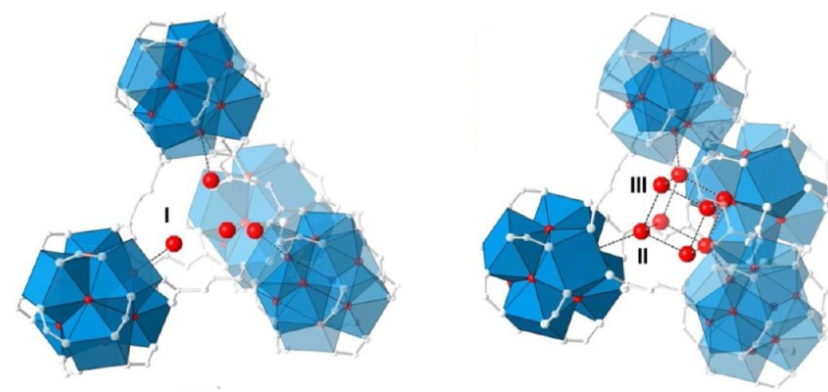

Fig. 9 Adsorption sites for water in UiO fumarate (MOF-801). Sites I and II are primary adsorption sites close to $\mathrm{Zr}_{6} \mathrm{O}_{4}(\mathrm{OH})_{4}$ units, while cubane water clusters form at higher water pressure upon filling sites III. Reprinted with permission from ref. ${ }^{24}$.

In the examples above, which correspond to hydrophilic CPO27 and $\mathrm{UiO}-66$ whose pores are of a size $\sim 1 \mathrm{~nm}$, water adsorption follows a pore-filling mechanism similar to that observed for zeolites. $^{85}$ For adsorbents with larger pores, capillary condensation mechanism takes place. The critical diameter $D_{\mathrm{c}}$ above which capillary condensation is observed is given by the following equation (in contrast, below this critical diameter, pore filling is reversible and continuous): ${ }^{85}$

$$
D_{\mathrm{c}}=4 \sigma T_{\mathrm{c}} /\left(T_{\mathrm{c}}-T\right)
$$

where $\sigma=2.8 \AA$ is roughly the size of the water molecule, $T$ the temperature, and $T_{\mathrm{c}}=647 \mathrm{~K}$ the bulk critical temperature for water. $D_{\mathrm{c}}=2.0 \mathrm{~nm}$ for water adsorption at room temperature. This value was estimated from Eq. (1) which has been shown to describe both molecular simulations and experiments on adsorption in porous materials. ${ }^{86}$ For porous solids with pores larger than $2 \mathrm{~nm}$, water adsorption isotherms exhibit step-wise adsorption due to capillary condensation, which is typical of class $\mathrm{V}$ adsorption isotherms as classified by Brunauer, Deming, Deming, and Teller. ${ }^{87,} 88$ Because of the irreversibility of capillary condensation, most adsorption isotherms for nanoporous materials with large pores are always accompanied with a hysteresis loop between the adsorption and desorption branches. The adsorption-desorption isotherms of MCM-41 with a pore size of $3.6 \mathrm{~nm}$ illustrates the typical " $\mathrm{S}$ " shape profile and the hysteresis loop typically found for mesoporous adsorbents (Fig. 10). ${ }^{89}$ The water adsorption isotherms of MIL-101 with pore sizes of 2.9 and $3.4 \mathrm{~nm}$ follow a similar step-wise adsorption and large water uptakes. For adsorption isotherms measured with high resolution, a two-step process is observed which is thought to arise from the filling of the $2.9 \mathrm{~nm}$ pores closely followed by that of the $3.4 \mathrm{~nm}$ pores. ${ }^{90}$ In the case of mesoporous silica, the first adsorption isotherm deviates from successive adorptiondesorption isotherm cycles. This is due to the hydroxylation of the surface of the silica upon the first adsorption cycle which generates a more hydrophilic adsorbent. ${ }^{91}$ As a consequence, for the subsequent measurements, the water uptake is significantly larger at low water partial pressure which results in the decrease of the apparent pore diameter and thus the decrease of the capillary condensation pressure. This principle of surface 
modification - adsorption property relationship is general and will be discussed later in the case of surface functionalisation of MOFs. The mechanisms of water adsorption in Cr-MIL-100 and Cr-MIL-101 have been studied by means of Monte Carlo molecular simulation. ${ }^{92} \mathrm{~A}$ marked difference was found between fluorinated and hydroxylated $\mathrm{Cr}^{3+}$ clusters, which illustrates that the partial charge at the nodes drives the hydrophilicity of the surface and, thus, the shape of the adsorption isotherm at low water pressure. At higher loadings, water-water interactions become dominant and irreversible capillary condensation occurs. Gascon and co-workers have shown that the accuracy of molecular simulation is very sensitive to the model parameters for the adsorbate-adsorbate interactions. ${ }^{92}$ Volumetric and calorimetric measurements on MIL-100 confirm the water uptake mechanism e.g. nucleation-growth followed by capillary condensation at larger pressure. ${ }^{93}$ The adsorption enthalpies decrease from $\sim-80 \mathrm{~kJ} / \mathrm{mol}$ to $\sim-45-50 \mathrm{~kJ} / \mathrm{mol}$ when the coverage increases from 0 to $<20 \%$ (corresponding to an uptake of about $0.1 \mathrm{~g} / \mathrm{g})$. At larger coverage, the heat of adsorption remains constant to a value close to the evaporation enthalpy of water $\sim 44$ $\mathrm{kJ} / \mathrm{mol}$ at $25^{\circ} \mathrm{C}$.
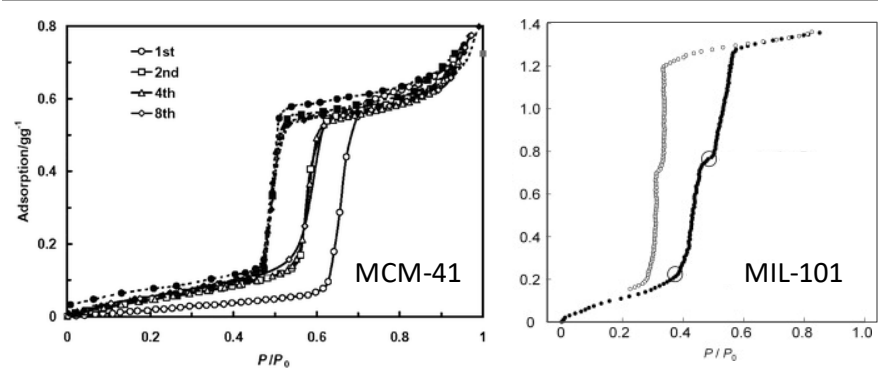

Fig. 10 Adsorption-desorption cycles of water at $298 \mathrm{~K}$ on (left) MCM-41 with a pore size of $3.6 \mathrm{~nm}$ and (right) Cr-MIL-101. Reprinted with permission from refs. ${ }^{89}$ and ${ }^{90}$, respectively.

In conclusion, despite somewhat different adsorption mechanisms, MOF share common features with porous oxides or carbons. As in the case of silicate-based solids, inorganic clusters in MOFs (such as UiO, CPO-27, HKUST-1, MIL100/101) can be dehydrated and rehydrated upon appropriate hydrothermal treatment. Physisorption rather proceeds through a nucleation-growth process of small water clusters adsorbed on primary sites than layer/multilayer adsorption mechanism. ${ }^{24,71}$ Depending on the apparent pore size of the MOF, the water uptake in the center of the pore occurs through reversible and continuous pore-filling or through capillary condensation (irreversible and discontinuous). We note that, once the pores are filled, the confined water is quasi-liquid provided the pores are large enough. In this case, the dynamics of confined water has been investigated (see for instance. ${ }^{94}, 95$ Finally, it is worth mentioning that capillary condensation in MCM materials can be accompanied with a deformation of the silica framework due to capillary forces which apply to the wall. ${ }^{96,} 97$ The silica host shrinkage due to water adsorption is somehow similar to the breathing of Al-MIL-53 upon hydration although the nature of the forces and the mechanisms of the flexibility differ. ${ }^{98}$ Indeed, as discussed above, for adsorbents with pore size smaller than 2 $\mathrm{nm}$, the presence of a hysteresis loop between the adsorption and desorption branches cannot be assigned to the irreversibility of capillary condensation but to a deformation of the framework due to guest-host interactions (for a recent perspective article on adsorption-induced deformation of MOF, see Ref. ${ }^{99}$ ).

The originality of water adsorption properties in MOFs lies in the very diverse profiles of adsorption-desorption isotherms. This is due to the fact that MOFs exhibit a great diversity in terms of pore size, pore structure, inorganic clusters, and chemical functionality. ${ }^{100}$ As a result, MOF can exhibit water uptake profiles which are typically found for zeolites, mesoporous silica, and carbons. Finally, it should be emphasized that sample pretreatment prior to adsorption experiments is a key issue when MOFs are considered. For instance, in the case of water adsorption in flexible Gallium-based MIL-53 MOF, it was shown that the shape of the adsorption isotherm strongly depends on the initial activation conditions. ${ }^{101,} 102$ The next section describes and discusses water adsorption-desorption isotherms for a non exhaustive yet representative set of MOF materials.

\subsection{Water adsorption-desorption isotherms}

Unless specified otherwise, the water adsorption isotherms discussed in what follows were measured at $298 \mathrm{~K}$. The uptakes are plotted as a function of the relative humidity $\mathrm{p} / \mathrm{p}^{\circ}\left(\mathrm{p}^{\circ}\right.$ corresponds to the bulk saturating vapor pressure at the measurement temperature). The use of relative pressures allows an easier comparison of adsorption isotherms recorded at slightly different temperatures. In this review, the adsorption isotherms are described and discussed by comparing two different quantitative indexes of hydrophilicity/hydrophobicity which can be estimated from water adsorption data measured at one temperature. The first indicator is the water adsorption capacity $\mathrm{C}_{\mathrm{H} 2 \mathrm{O}}$ (in $\mathrm{cm}^{3}$ of water per $\mathrm{g}$ of sample) which mainly reflects the pore volume at the exception of superhydrophobic microporous solids for which water adsorption proceeds by liquid water intrusion. ${ }^{103}$ The second indicator is the relative pressure $\alpha=$ $\mathrm{p} / \mathrm{p}^{\circ}$ at which half of the total water capacity is reached; ${ }^{69} \alpha$ increases with increasing the hydrophobicity of the porous solid. The advantages of this indicator are that (i) it is a priori independent of the water adsorption capacity, (ii) it is normalized $(0<\alpha<1)$ and (iii) it captures relatively well the relative pressure of the inflexion point for "S"-shaped adsorption isotherms (type V). Other relevant indicators are the heat of adsorption at low coverage and Henry's constant $\left(\mathrm{K}_{\mathrm{H}}\right)$ which corresponds to the slope of the adsorption isotherm at very low water partial pressures (where the adsorbed amount increases linearly with water pressure). However, these data are more rarely reported in the literature which makes a consistent comparison between different sets of data less convenient.

Water adsorption-desorption isotherms of $\mathrm{Ni}$ - and $\mathrm{Mg}-\mathrm{CPO}-$ 27 are reported in Fig. 11. Both adsorption isotherms exhibit a type-I profile characterized by a large water uptake at low pressure and a long saturation plateau as usually found for zeolites. The very large adsorption capacity at low pressure makes these porous solids the greatest hydrophilic adsorbents in 
the domain of physisorption. It should be emphasized that the capacity of Mg-CPO-27 is somewhat larger than for Ni-CPO-27 because of the larger molar mass of the later.
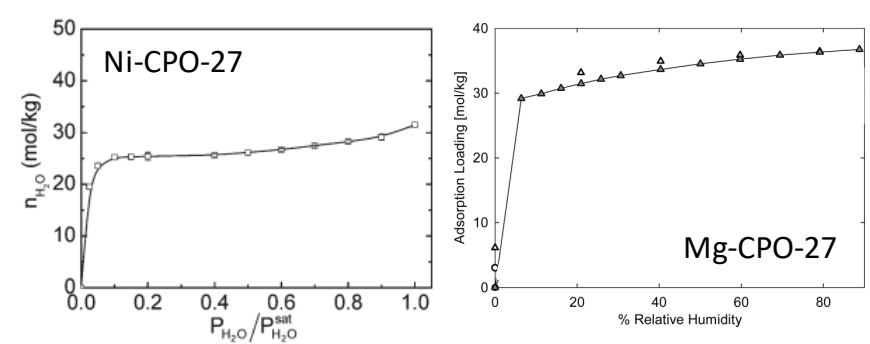

Fig. 11 Water adsorption isotherms at $298 \mathrm{~K}$ on isoreticular CPO-27 solids: (left) $\mathrm{Ni}-\mathrm{CPO}-27$ and (right) Mg-CPO-27. Reprinted with permission from refs. ${ }^{104}$ and ${ }^{5}$, respectively.

The pore structure of MIL-125 is a tridimensional network made up of two types of cage whose accessible diameters are 0.6 $\mathrm{nm}$ and $1.2 \mathrm{~nm}$. Similarly, UiO-66 exhibits two types of cavity of diameter $0.75 \mathrm{~nm}$ and $1.2 \mathrm{~nm}$. Both cavities are made of corner sharing inorganic clusters and terephathalate-based linkers. Hence, the families of UiO-66 and MIL-125 solids are microporous solids which exhibit similar tridimensional pore structure and bimodal pore size distribution although their clusters are made of different cations and arrangements: $\mathrm{Zr}_{6} \mathrm{O}_{4}(\mathrm{OH})_{4}$ and $\mathrm{Ti}_{8} \mathrm{O}_{8}(\mathrm{OH})_{4}$ for $\mathrm{UiO}-66$ and MIL-125, respectively. As a result, UiO-66 and MIL-125- $\mathrm{NH}_{2}$ exhibit very similar water adsorption-desorption isotherms (Fig. 12). The adsorption isotherms exhibit a "S" shape with a small uptake at low pressure followed by an adsorption step with inflexion points at $\mathrm{p} / \mathrm{p}^{\circ}=0.3$ and 0.2 for MIL-125- $\mathrm{NH}_{2}$ and UiO-66, respectively. For the two solids, the desorption branches do not perfectly coincide with the adsorption branches. For such small pore sizes, well below the critical diameter of $2.0 \mathrm{~nm}$ at $25^{\circ} \mathrm{C}$, irreversibility associated with capillary condensation can be ruled out. These hysteresis loops have been tentatively assigned to minor modifications of the porous structure due to guest-host interactions and network flexibility. ${ }^{69}$

Water adsorption-desorption cycles were carried out for UiO-66 in order to evaluate the effect of hydration-dehydration on its adsorption properties. These adsorption cycles were also intended to check the stability of the framework upon cycling. Two water adsorption isotherms were obtained at $298 \mathrm{~K}$ with a regeneration step between them at $353 \mathrm{~K}$ for 2 hours under inert gas flow. The two adsorption isotherms obtained coincide (Fig. 12 , right panel). The water uptake at low pressures is low until the relative humidity reaches $25 \%$. Between $30 \%$ and $50 \%$ relative humidity, the water adsorbed amount increases rapidly to reach a plateau at around $0.37 \mathrm{~g} . \mathrm{g}^{-1}$. Assuming confined water has a density close to the bulk liquid density, the pore volume calculated from the water adsorption isotherm is $0.35 \mathrm{~cm}^{3} \cdot \mathrm{g}^{-1}$. This pore volume is close to that obtained from nitrogen adsorption at $77 \mathrm{~K}$. Additional cycling was carried out with soft evacuation in order to avoid dehydration of the $\mathrm{Zr}_{6} \mathrm{O}_{4}(\mathrm{OH})_{4}$ cluster when formed. The second and following cycles are shifted with respect to the first one. However, for a given relative pressure, the four consequent runs show the same water uptakes. The small shift of the adsorption isotherm to lower pressure during the first three cycles indicates a higher degree of hydrophilicity in agreement with the hydration process on the inorganic cluster from $\mathrm{Zr}_{6} \mathrm{O}_{6}$ to $\mathrm{Zr}_{6} \mathrm{O}_{4}(\mathrm{OH})_{4}$ (which corresponds to a mass variation of $1.35 \%$ only).
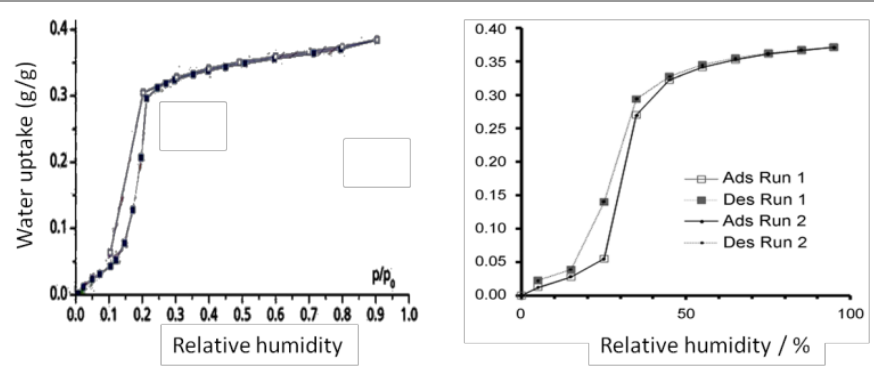

Fig. 12 (left) Water adsorption/desorption isotherms for MIL-125- $\mathrm{NH}_{2}$ measured at $\mathrm{T}=25^{\circ} \mathrm{C}$ (adsorption: filled symbols; desorption: empty symbols); (right) Two consecutive water adsorption/desorption cycles for UiO-66 with regeneration at $353 \mathrm{~K}$ under an inert atmosphere. Reprinted with permission from refs. ${ }^{83}$ and ${ }^{79}$, respectively.

Water adsorption-desorption in mesoporous MOF is illustrated in Fig. 13 in which we consider MIL-100 and MIL101 solids. These materials are built from the assembly of trinuclear clusters of trivalent cations among $\mathrm{Cr}^{3+}, \mathrm{Fe}^{3+}, \mathrm{Al}^{3+}$ and terephtalate-based linkers for MIL-101 and trimesate for MIL100. The porous structures are tridimensional arrangements of accessible mesopores of a size $2.5 \mathrm{~nm}$ and $2.9 \mathrm{~nm}$ for MIL-100 and $2.9 \mathrm{~nm}$ and $3.4 \mathrm{~nm}$ for MIL-101. Adsorption-desorption water isotherms for MIL-100 and MIL-101 with different metal cations were reviewed by Henninger et al. ${ }^{31,105}$ All MIL-100/101 solids exhibit similar water adsorption isotherms which are characterized by a very large water uptake at relative humidities ranging from $\mathrm{p} / \mathrm{p}^{\circ}=0.25$ to 0.60 . The total water capacity is smaller for MIL-100 (about 0.8 g.g ${ }^{-1}$ ) than for MIL-101 (1.2 g.g$\left.{ }^{1}\right)$, as expected from the pore volumes for these two solids. ${ }^{61,90}$ Irreproducible results regarding the total capacity have been also reported for different Cr-MIL-101 samples while the type of adsorption isotherm remains unchanged. Such discrepancies may originate from lower sample crystallinity or incomplete pore evacuation prior to adsorption measurement. While the water adsorption isotherms for Fe- and Cr-MIL-100 solids are very similar, the adsorption isotherm for Al-MIL-100 leads to a different water total capacity. This is believed to be due to the presence of 1,3,5-benzenetricaboxylic acid in the cavities which is more difficult to evacuate. ${ }^{74}$

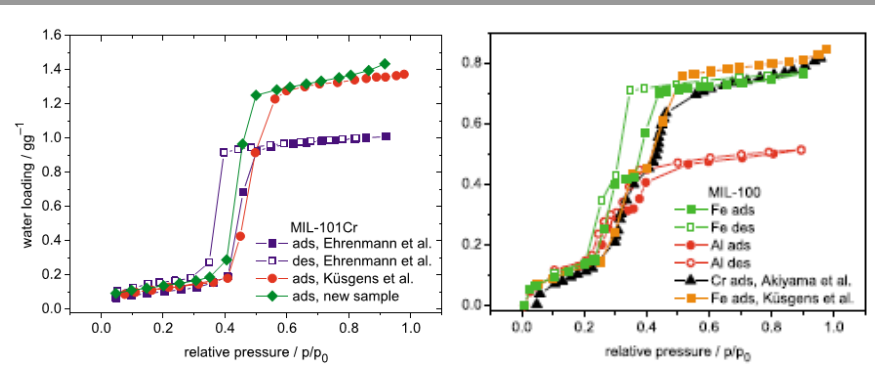


Fig. 13 Water adsorption-desorption isotherms for different Cr-MIL-101 samples (left) and for isostructural MIL-100 made from $\mathrm{Fe}^{3+}, \mathrm{Cr}^{3+}$ or $\mathrm{Al}^{3+}$ (right). Reprinted with permission from refs. ${ }^{105}$ and ${ }^{31}$, respectively.

The adsorption properties of MOFs can be tuned by modifying the surface properties of their porous framework. It can be achieved by (1) direct synthesis of isoreticular MOF starting from functionalised linkers bearing various hydrophylic or hydrophobic groups or (2) post-synthesis modification using a reactive center on the MOF for grafting chemical functions. MOF made from 1,4-benzene dicarboxylic acid are outstanding model compounds because most of them can be obtained in one or two synthesis steps with diverse pending organic functions. This has led to the concept of isoreticular solids. ${ }^{27}$ The effects of surface decoration on gas adsorption properties were illustrated for many materials such as MOF-5, ${ }^{26,28}$ MIL-53, ${ }^{106}$ MIL-88 ${ }^{107}$ and UiO-66. ${ }^{108-110}$ Water adsorption isotherms on isoreticular $\mathrm{Cr}-$ MIL-101, with their aromatic ring functionalized by amino ($\mathrm{NH}_{2}$ ), nitro $\left(-\mathrm{NO}_{2}\right)$ and sulfonic acid $\left(-\mathrm{SO}_{3} \mathrm{H}\right)$ groups, were compared. ${ }^{61,90}$ The partial pressures at which the inflection point is observed are $\alpha=0.31$ for the hydrophylic material MIL-101$\mathrm{NH}_{2}$ and $\alpha=0.45$ for the hydrophobic material MIL-101- $\mathrm{NO}_{2}$ (Fig. 14). While the adsorption pressures are very sensitive to the linker chemistry, water desorption in MIL-101 samples takes place at similar pressures, $\mathrm{p} / \mathrm{p}^{\circ} \sim 0.32-0.37 .{ }^{69}$ Consequently, the hysteresis loops are wider for Cr-MIL-101 and Cr-MIL-101-NO than for Cr-MIL-101-NH2. These observations can be understood as follows. Because of its larger surface hydrophilicity, water adsorption prior to capillary condensation in Cr-MIL-101- $\mathrm{NH}_{2}$ is larger than in the two other materials. At $\mathrm{p} / \mathrm{p}^{\circ}=0.3$, the adsorbed amount of water in Cr-MIL-101-NH 2 is approximatively twice that in Cr-MIL-101-NO 2 . As a result, the cavity which gets filled upon capillary condensation (corresponding to the pore volume less the volume occupied by the adsorbed water molecules) is smaller for Cr-MIL-101- $\mathrm{NH}_{2}$ than for Cr-MIL-101 and Cr-MIL-101-NO . In turn, because of its smaller size, such a cavity becomes filled at a lower capillary condensation pressure than for the other materials. In contrast, the desorption pressures for these three materials are very similar; this is due to the fact that, since the sizes of the fully filled pore are very similar, desorption takes place at a similar pressure.

Tuning the adsorption properties of MOF by grafting short polyols and ethylenediamine on the coordinative unsaturated sites (cus) was demonstrated by Wickenheisser et al. for MIL$100 .{ }^{111}$ Although grafting leads to a decrease in the pore volume, water adsorption isotherms of the modified compounds Cr-MIL100-EG, Cr-MIL-100-DEG and Cr-MIL-100-EN show an enhanced uptake of water at lower partial pressures and no loss of total water uptake capacity compared to non-modified $\mathrm{Cr}$ MIL-100.

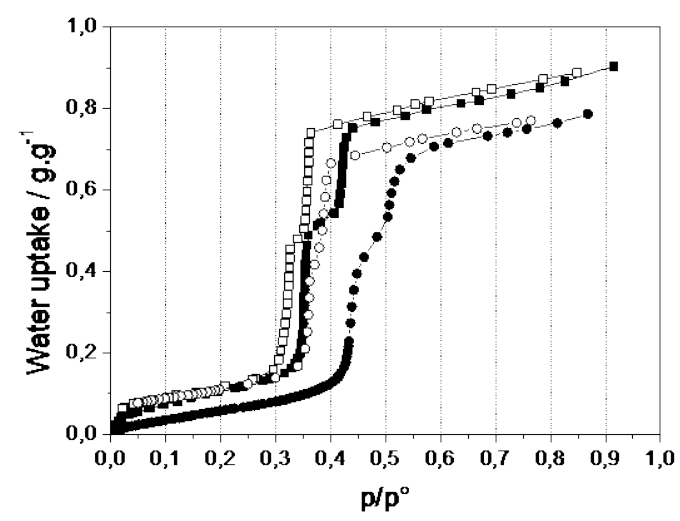

Fig. 14 Water adsorption-desorption isotherms of Cr-MIL-101- $\mathrm{NH}_{2}$ (square) and Cr-MIL-101- $\mathrm{NO}_{2}$ (circle). The full and empty symbols are the adsorption and desorption data, respectively. Reprinted with permission from ref. ${ }^{69}$.

The effect of surface modification on water adsorption was studied by Cmarik et al. by adding an amino subsituent onto UiO-66. ${ }^{108}$ The decoration of the porous walls by $-\mathrm{NH}_{2}$ groups enhances the hydrophilicity as it allows H-bonding interaction which is reflected by the larger uptake at low relative humidity (Fig. 15).

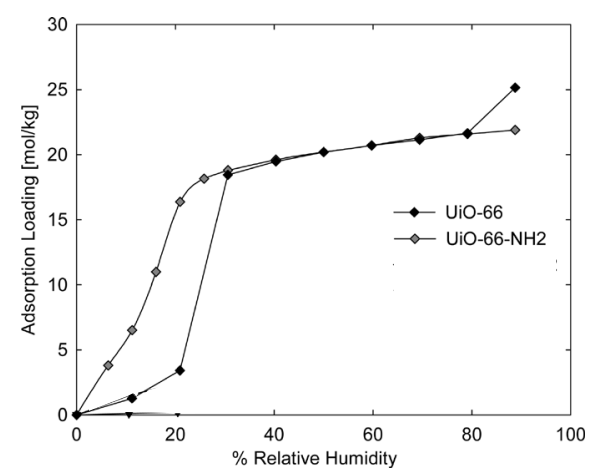

Fig. 15 Adsorption of water on UiO-66 and UiO-66- $\mathrm{NH}_{2}$ at $298 \mathrm{~K}$. Reprinted with permission from ref. ${ }^{5}$.

Stock and coworkers also studied the effect on water adsorption of surface modification on isostructural CAU-10 using a large variety of functions $\left(-\mathrm{NO}_{2},-\mathrm{NH}_{2},-\mathrm{CH}_{3},-\mathrm{OCH}_{3}\right.$, and -OH groups). ${ }^{112}$ The general chemical formula of these solids is [Al $(\mathrm{OH})(1,3$-benzenedicaroxylate)]. The inorganic building unit of the CAU-10 framework is a chain of cis-connected, cornersharing $\mathrm{AlO}_{6}$ polyhedra. The resulting solid is a two dimensional porous network with square-shaped sinusoidal channels. These intersecting channels have a diameter of $\sim 0.7 \mathrm{~nm}$. 


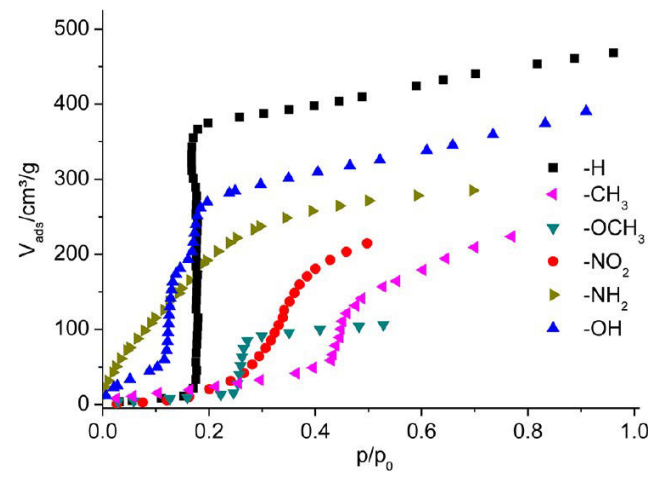

Fig. 16 Water adsorption isotherm at $298 \mathrm{~K}$ of a series of $\mathrm{CAU}-10$ functionalised by $-\mathrm{NO}_{2},-\mathrm{NH}_{2},-\mathrm{CH}_{3},-\mathrm{OCH}_{3}$, and $\mathrm{OH}$-groups. Reprinted with permission from ref. ${ }^{112}$.

The decoration of the CAU-10 walls by the different organic groups strongly modifies the maximum water capacity and the shape of the adsorption isotherm (Fig. 16). As expected, the water maximum capacity decreases with increasing the size of the functionalization group. Pristine CAU-10 exhibits an abrupt uptake in a single adsorption step. Such an adsorption profile, which was also reported for In-MIL-68, is rare. ${ }^{69}$ Hydrophilic substituents $\left(-\mathrm{NH}_{2},-\mathrm{OH}\right)$ shift adsorption to lower relative humidity whereas hydrophobic substituents $\left(-\mathrm{NO}_{2},-\mathrm{OCH}_{3}\right.$, $\mathrm{CH}_{3}$ ) shift the inflection of the " $\mathrm{S}$ " curve to larger relative pressures.

The effects of pore decoration by organic groups on water adsorption were also studied using isoreticular imidazolate and triazolate-based MOFs. The hyperhydrophobic features of ZIF8 were first highlighted by the group of Kaskel and later applied for alcohol separation by Denayer. ${ }^{25,}{ }^{113}$ ZIF-8 does not show significant water uptake even at pressures close to the bulk saturation vapour pressure. Similar results were obtained on ZIF71 which is made from 4,5-dichloroimidazolate. ${ }^{114}$ Such behaviours, which are typical of hyperhydrophobic zeolites, ${ }^{103}$ arise from the absence of polar centres (hydrogen bond groups at the surface and uncoordinated centres from the inorganic pattern) together with the very small pore windows of the sodalite cavity $(\sim 0.3 \mathrm{~nm}) .{ }^{115}$

The microporous solids ZIF-90 and SIM-1 are isoreticular to ZIF-8 and possess both an aldehyde group on the 5-position for SIM-1 (on the back of the imidazolate) and on the 2-position for ZIF-90 (between the two nitrogen of the imidazolate ring). The aldehyde functionalized ZIF exhibits an "S"-shaped adsorption isotherm (Fig. 17). Water uptakes of $0.12 \mathrm{~cm}^{3} / \mathrm{g}$ and $0.29 \mathrm{~cm}^{3} / \mathrm{g}$ are observed for SIM-1 and ZIF-90, respectively. Such water uptakes are consistent with the pore volumes measured for these solids. ${ }^{116,117}$ The hysteresis observed for SIM-1 is assumed to arise from the flexibility of ZIF porous solids upon guest adsorption. ${ }^{118-120}$

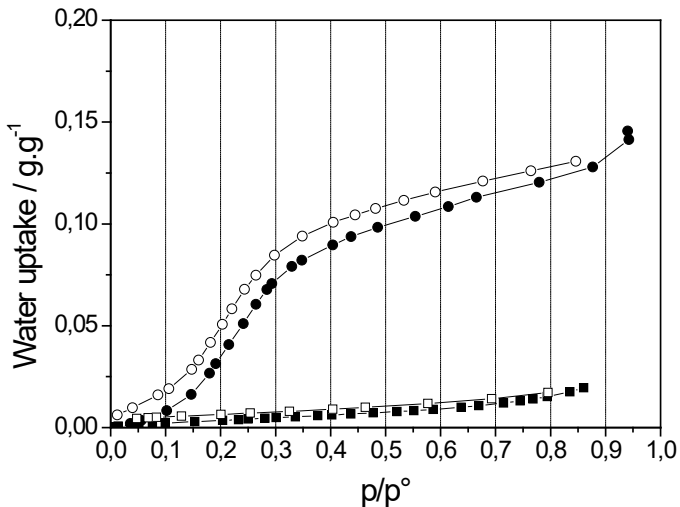

Fig. 17 Water adsorption-desorption isotherms at 298K for ZIF-8 (squares) and SIM-1 (circles). Closed and open symbols correspond to adsorption and desorption respectively. Reprinted with permission from ref. ${ }^{69}$

Liquid water can penetrate the microporous structure of ZIF8 upon applying large pressures. A water uptake of $\sim 0.5 \mathrm{~mL} . \mathrm{g}^{-1}$, corresponding to the porous volume measured by nitrogen adsorption, (see Table 1), occurs at about $27 \mathrm{MPa}$ (Fig. 18). ${ }^{121}$ The water intrusion-extrusion isotherm shows a narrow hysteresis as extrusion occurs at a slightly lower pressure than the intrusion pressure (for a detailed discussion on intrusion in porous media, see Refs ${ }^{122,123}$. The heat of adsorption, which was estimated from Grand Canonical Monte Carlo simulations at about $52 \mathrm{~kJ}$ mol.-1, is somewhat larger than the bulk vaporization enthalpy of water and therefore indicates the adsorbed phase is dense with strong water-water interactions. ${ }^{115}$

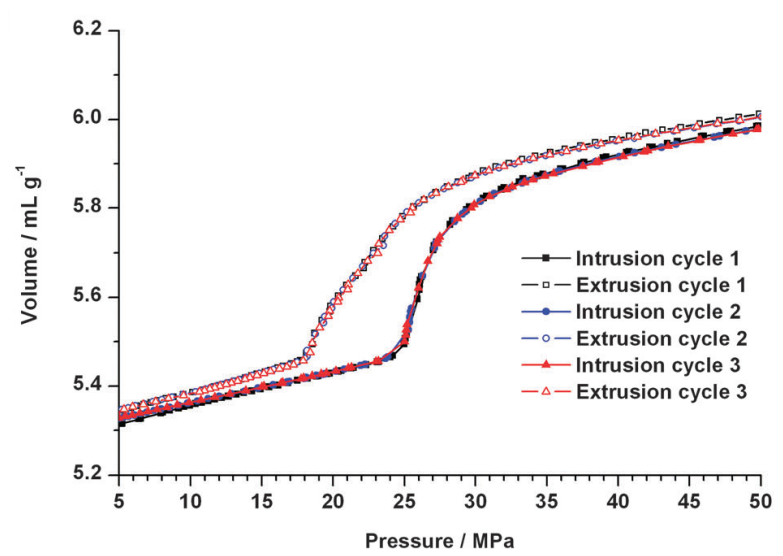

Fig. 18 Water intrusion-extrusion isotherms for ZIF-8. Pressures are in the range from 5 to $50 \mathrm{MPa}$. Reprinted with permission from ${ }^{121}$.

Water in ZIF-8 displays an interesting shock-absorber behaviour. The stored energy is close to $13.3 \mathrm{~J} / \mathrm{gram}$ of solid, which is twice the value found for water in zeolites with equivalent pore apertures $(2.4-4.4 \AA)$. The value for hydrophobic MOF is close to FER, MTW, and TON-type zeolites but with a much smaller intrusion pressure. This noticeable difference is assumed to be due to the lower stiffness, shear modulus, and Young modulus for ZIF-8. ${ }^{124}$ This promising 
result paves the way for new applications in the field of energy storage.

Although pyrazolate-based MOFs exhibit very high stability in water, their water adsorption characteristics remain largely unexplored. Isostructural series of six distinct pyrazolate-based MOFs, Zn(NDI-X), were investigated by Wade et al. ${ }^{125}$ These solids possess infinite chains of tetrahedral $\mathrm{Zn}^{2+}$ ions bridged by pyrazolate groups and have $\sim 1.6 \mathrm{~nm}$ channels with functionalised naphthalenediimide linkers lining the channel surface. The resulting adsorption isotherms are all of type V (Fig. 19). Post-synthetic oxidation of $\mathrm{Zn}(\mathrm{NDI}-\mathrm{SEt})$ with dimethyldioxirane was used to generate ethyl sulfoxide and ethyl sulfone groups, which render the channels more hydrophilic as evidenced by shifts in water uptake to the $30-40 \%$ relative humidity range.

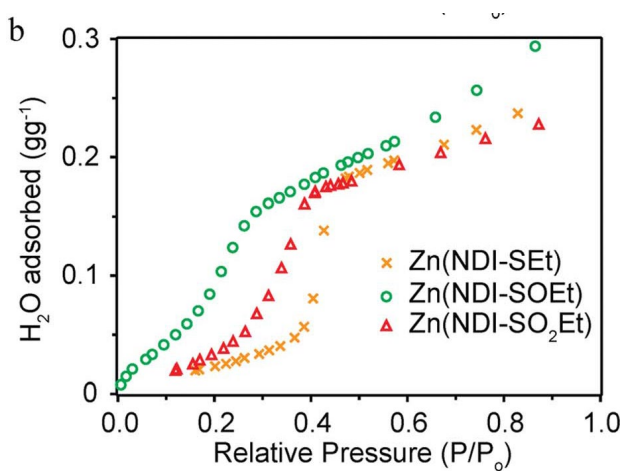

Fig. 19 Water adsorption isotherms for Zn(NDI-SEt), Zn(NDI-SOEt), and Zn(NDI$\mathrm{SO}_{2} \mathrm{Et}$ ) measured at $293 \mathrm{~K}$ Reprinted with permission from ref. ${ }^{125}$.

While the dipolar moment of the linker has been shown to be correlated with $\mathrm{CO}_{2}$ adsorption for a series of isoreticular sodalite type ZIF, the hydrophobic parameter $\pi$ was tentatively proposed as a descriptor of the water adsorption property of MOF by the groups of Kitagawa ${ }^{90}$ and Dinca. ${ }^{125} \pi$ is calculated using Eq. (2) where $\mathrm{P}_{\mathrm{H}}$ and $\mathrm{P}_{\mathrm{x}}$ are the partition coefficients of the parent and derivative compounds, respectively: ${ }^{126}$

$$
\pi=\log \mathrm{P}_{\mathrm{x}}-\log \mathrm{P}_{\mathrm{H}}
$$

While $\pi$ is related to the hydrophobicity for the isoreticular series of MIL-101 (-H, $\left.\mathrm{NH}_{2},-\mathrm{NO}_{2}\right)$, it partially describes the effect of chemical modification for the triazolate series $\mathrm{Zn}(\mathrm{NDI}-\mathrm{X})$ with $\mathrm{X}=-\mathrm{SEt}$, $-\mathrm{SOEt}$, $-\mathrm{SO}_{2} \mathrm{Et}$. The water adsorption step for $\mathrm{Zn}(\mathrm{NDI}-$ $\mathrm{SOEt})$ is clearly shifted with respect to that for $\mathrm{Zn}\left(\mathrm{NDI}-\mathrm{SO}_{2} \mathrm{Et}\right)$, despite similar hydrophobic parameters for the $-\mathrm{SOEt}$ and $\mathrm{SO}_{2} \mathrm{Et}$ groups. However, $\pi$, which derives from water-octanol partitioning, differs from hydrophilicity data determined in other solvent mixtures and therefore leads to biased predictions.

The effects of pore decoration by organic substituents on water adsorption are more complex to unravel in the case of flexible porous MOFs, also referred to as soft MOFs. ${ }^{127}$ Breathing induced by $\mathrm{CO}_{2}$ adsorption is well known for isoreticular series such as for MIL-53, ${ }^{106}$ MIL-88 ${ }^{128}$ and junglegym-like porous solids. ${ }^{129}$ However, breathing induced by water adsorption is much less documented in MOFs. Rare examples show that breathing upon water adsorption can be controlled or switched on/off by modification of the porous surface through grafting of substituents onto the framework. Water adsorptiondesorption isotherms for a series of isoreticular Al- and Fe-MIL53 are reported in Fig. 20. ${ }^{130}$ Adsorbed amounts are reported in mol of water adsorbed per metal (either Al or Fe) unit. Al-MIL53- $\mathrm{NH}_{2}$ exhibits reversible type-I adsorption isotherm which reaches a maximum of one water molecule per Al. This maximum adsorption capacity corresponds to the hydrated structure in which a water molecule is located at the centre of the channel where it interacts with the two opposite $\mathrm{AlO}(\mathrm{OH})$ chains. ${ }^{98}$ The desorption branch of Al-MIL-53 is superimposed with the adsorption and desorption branches of the former. The difference between Al-MIL-53 and Al-MIL-53-NH2 lies in the adsorption branch of the latter which describes an "S" shape (type V). As a consequence, water adsorption in Al-MIL-53 is not fully reversible. This phenomenon arises from the larger flexibility of MIL-53 as demonstrated by XRD studies and $\mathrm{CO}_{2}$ adsorption. ${ }^{131}$, 132 The total uptake for MIL-53-(COOH $)_{2}$ corresponds to two water molecules per metal unit, which suggests that a water molecule forms a hydrogen bond between two free carboxylic acid functions. The hysteresis loop observed in the water adsorption isotherm indicates strong guest-host interactions accompanied with structural modifications upon adsorption.

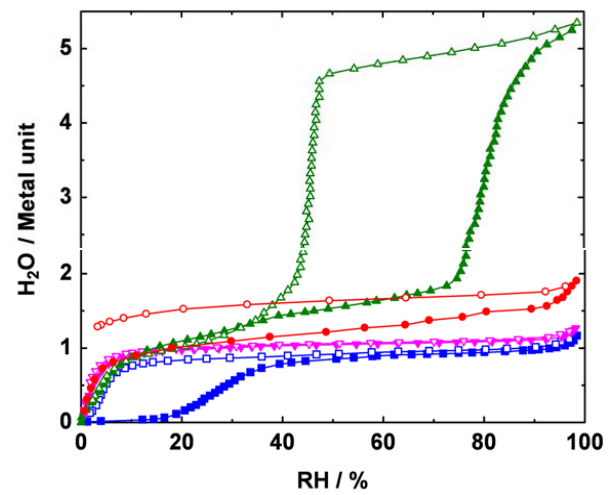

Fig. 20 Water adsorption (filled symbols) and desorption (open symbols) isotherms of dehydrated Al-MIL-53 (blue, $\mathbf{m}$ ), Al-MIL-53-NH 2 (pink, $\boldsymbol{\nabla}$ ), Al-MIL-53$\mathrm{OH}($ green, $\boldsymbol{\Delta})$ and Fe-MIL-53- $(\mathrm{COOH})_{2}(\mathrm{red}, \bullet)$ at 298K. Reprinted with permission from ref. ${ }^{130}$

In contrast to the other MIL-53 materials of this study, AlMIL-53-OH exhibits breathing upon increasing the water adsorbed amount from 1 to 2 water molecules per Al center. This abrupt uptake occurs at a relative humidity around $80 \%$. This stepwise adsorption corresponds to structure changes from a narrow-pore phase to a large-pore phase.

Water adsorption in Ga-MIL-53 is quite different from AlMIL-53 as the narrow-pore phase of Ga-MIL-53 is thermodynamically more stable at ambient temperature (in contrast to to Al-MIL-53). ${ }^{101,133,134}$ As a result, in contrast to AlMIL53, the water adsorption isotherm is fully reversible for GaMIL53. Four different regions are observed upon increasing the water vapour pressure: (i) swelling of the narrow-pore phase 
upon increasing the loading to $0.05 \mathrm{~mol} / \mathrm{mol}$; (ii) formation of an intermediate hydrated phase at $100 \mathrm{~Pa}$ at $298 \mathrm{~K}$, (iii) monohydration of the narrow-pore phase $\mathrm{Ga}(\mathrm{OH})(\mathrm{bdc})$, and (iv) transition to the large-pore phase (Fig. 21). ${ }^{102}$ The two narrowpore phases and narrow-pore monohydrated phase coexist in a relatively small pressure window.

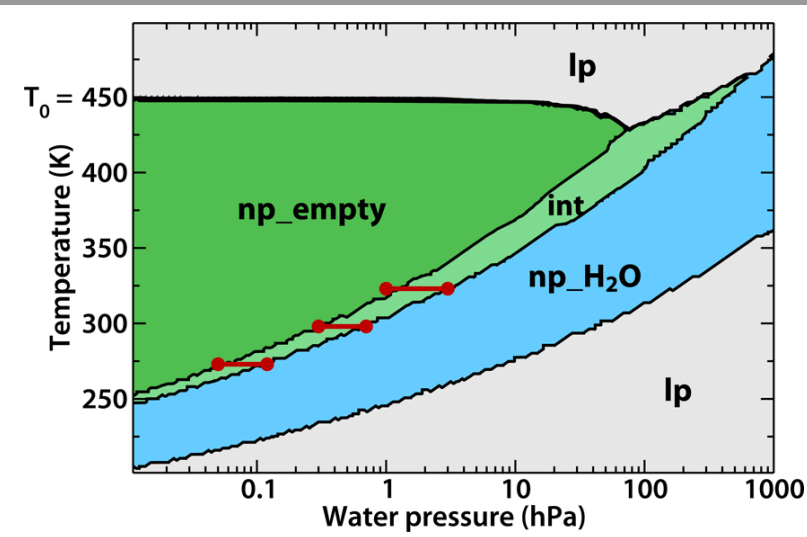

Fig. 21 Phase diagram (water pressure, temperature) of Ga-MIL-53 which shows the stability domains of the different structures. The red segments correspond to the experimental transitions. Reprinted with permission from ref. ${ }^{102}$.

By combining experimental data and molecular simulation, Coudert et al. have built a water vapour pressure-temperature diagram for the structural transitions of Ga-MIL-53. ${ }^{102}$ This phase diagram allows estimating the energy barrier for the transition between the different phases. The two first transitions from the narrow pore empty phase to the intermediate phase and to the monohydrated phase are characterized by very low free energy barriers due to their close structural proximity (around 0.1 $\mathrm{kJ} / \mathrm{mol}$ and $0.3 \mathrm{~kJ} / \mathrm{mol}$, respectively). These small energy barriers explain the lack of hysteresis upon adsorption-desorption cycles at low pressure. In contrast, the barrier for the narrow pore large pore transition is significantly larger with a value between 7 to $10 \mathrm{~kJ} / \mathrm{mol}$. While the breathing of MIL-53 MOFs induced by water has received attention, other MOFs have not been considered in details. Recently, Ortiz et al. have predicted the flexibility of NOTT-300 (wine-rack structure) using firstprinciples calculations. ${ }^{135}$ Solid solutions of soft porous MOF structures have shown water adsorption tunability by controlling the composition of the solid solution. The interdigitated CID-6 solid is a quite rigid porous framework whereas an isoreticular compound CID-5 made from different substituents is very flexible. ${ }^{136}$ Series of solids made from solid solutions of CID-5 and CID-6 with different ratios of substituent 5-nitroisophthalate and 5-methoxyisophthalate in the range $0.06<\mathrm{x}<0.92$ were synthesized. Given that CID-5 is nonporous (as determined by $\mathrm{N}_{2}$ adsorption at low temperature), it exhibits an irreversible gate-opening behaviour upon water adsorption while porous CID-6 shows a more linear and fully reversible water uptake. The water adsorption experiments clearly indicate that solid solutions of CID-5/6 exhibit gate-opening whose amplitude is directly related to the amount of CID-5 and CID-6 (Fig. 22).

The Table 1 reports the water adsorption data for a large variety of MOFs. As underlined above, the total uptake varies from $0.1 \mathrm{~cm}^{3} / \mathrm{g}$ for the most hydrophobic MOF (ZIF-8) to 1.4 $\mathrm{cm}^{3} / \mathrm{g}$ for the MOF with the largest pore volume (MIL-101). As expected, the porous volume and surface area calculated from the $\mathrm{N}_{2}$ adsorption isotherms are very well correlated. In contrast, some differences are observed between the porous volume seen by nitrogen adsorption and the water capacity. This shows that the specific behavior of some samples in the presence of water leads to large departures between their water capacity and the water amount expected on the basis of their porous volume. The index $\alpha$, which corresponds to the pressure at which pore filling occurs, is rather linked to the pore size. The functionalization of MOFs by polar groups (either amino or aldehyde) systematically leads to a shift to lower $\alpha .{ }^{69}$ This is consistent with the reduction of the apparent pore size close to the pore filling or condensation pressure since the adsorbed water layers occupy part of the cavities.
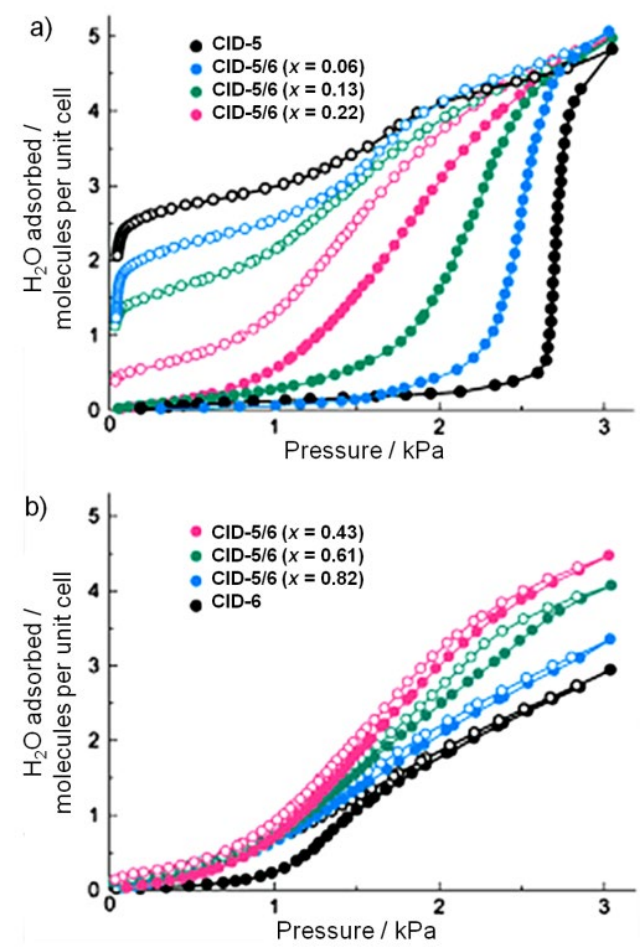

Fig. 22 Water adsorption (closed circles) and desorption (open circles) isotherms at $298 \mathrm{~K}$ for: a) CID-5 and solid solution CID-5/6 ( $x=0.06-0.22)$ and b) CID-5/6 $(x=0.43-0.82)$ and CID-6. Reprinted with permission from ref. ${ }^{136}$. 
Table 1. Summary of reported MOF porous features and water adsorption properties measured at 298K (unless specified).

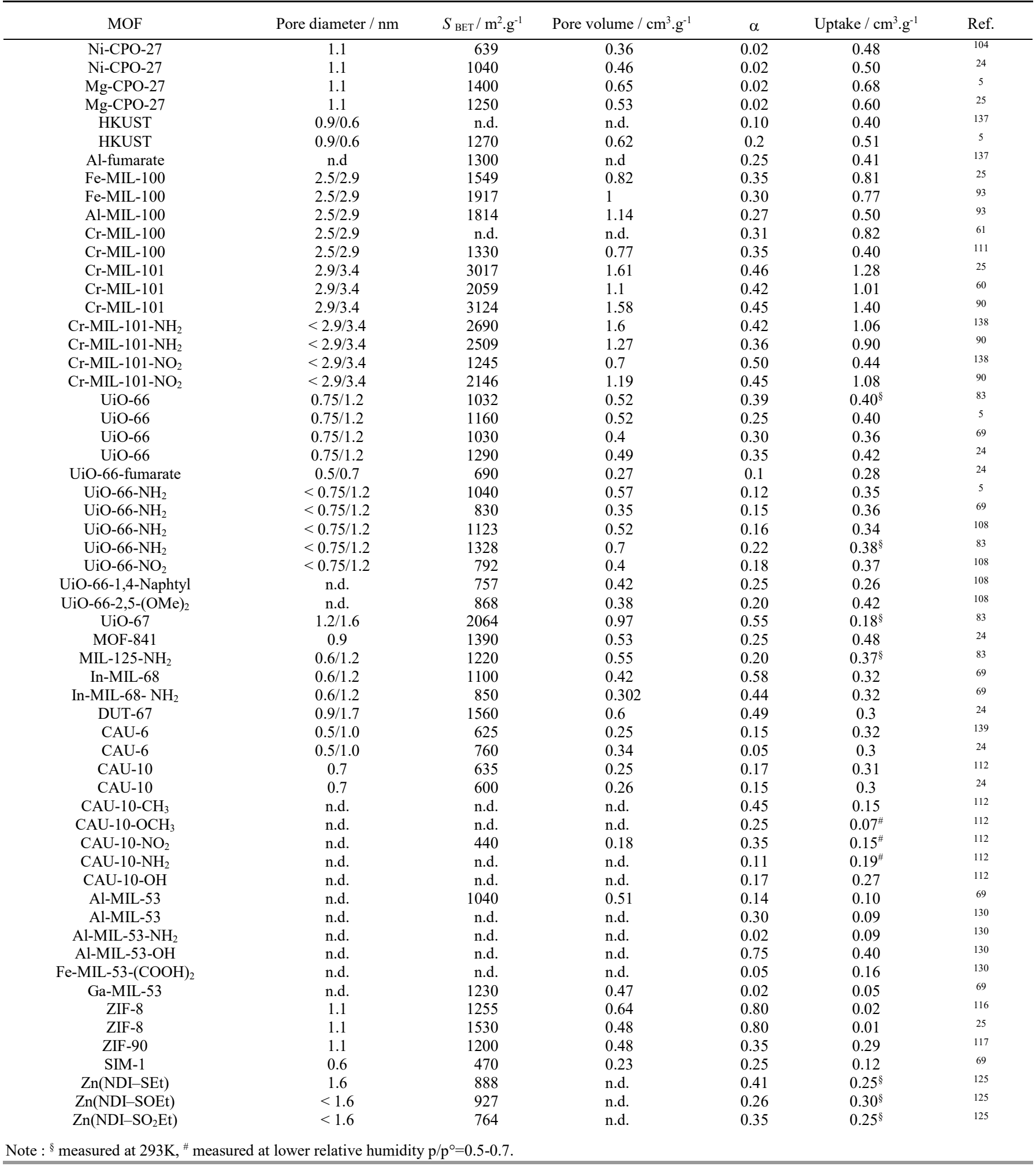

The interest in efficient cooling and heating technologies which use environmentally friendly refrigerants is rapidly growing. In addition, there is an increasing energy demand for summer air-conditioning and also data center cooling. Unlike traditional vapour-compression heat pumps, which rely entirely 
on electrical power, adsorption-based processes can exploit low temperature waste heat or solar collectors as primary energy sources. Solar thermal collectors or waste heat from industrial processes constitute very attractive thermally-driven adsorption chillers or adsorption heat pumps for the efficient use of lowtemperature heat. Reference papers on this emerging technology can be found in the literature. ${ }^{140,141} \mathrm{~A}$ few works on MOFs as water adsorbents for heat transformation are also available in the literature (for instance, see the works by Aristov and Henning, Janiak and coworkers, and others). ${ }^{138,}$ 142-144

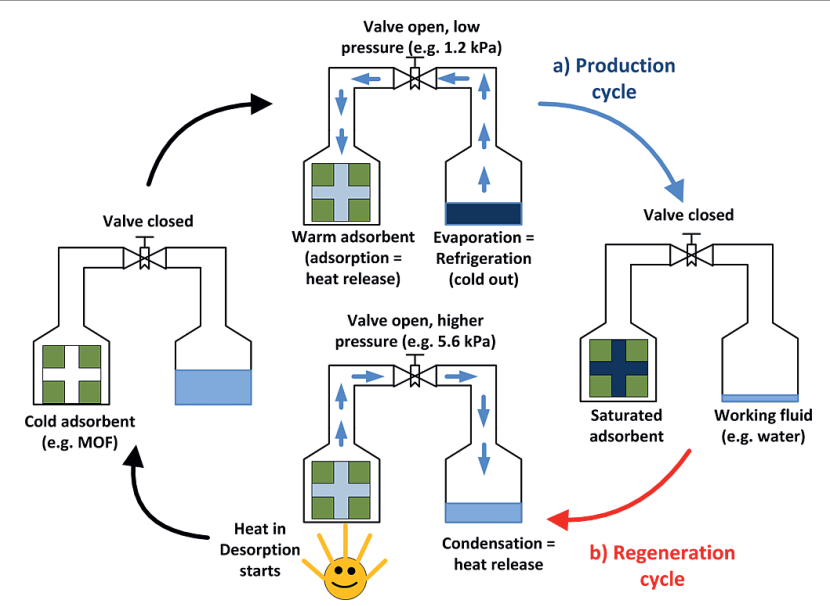

Fig. 23 Principle of heat transformation. Reprinted with permission from ref. ${ }^{105}$.

In adsorption-based processes, the heat transformation is called adsorption chillers when cooling application is wanted and heat pumps for heat generation. The basic principle of a heat transformation unit operating by adsorption and desorption of a working fluid is illustrated in Fig. 23. ${ }^{105}$ Fig. 24 shows the data recorded by a thermal camera which measures the temperature increase resulting from the heat generated while water adsorption takes place in an adsorbent containing vessel. ${ }^{31}$ In contrast, water evaporation absorbs heat and leads to a temperature decrease in the opposite vessel. During the regeneration process, heat from a high temperature source (e.g. solar collector, waste heat, etc.) is used to desorb water from the porous solid. The released water vapour condenses at an intermediate temperature level with the heat of condensation released to the environment in the cooling case. The thermodynamics of this system can be described by a cycle consisting of two isosters and two isobars. ${ }^{145}$ The working conditions are determined by three temperature levels: (i) high temperature for regeneration, (ii) medium temperature for condensation and cooling of the adsorption process, and (iii) low temperature in the evaporator. ${ }^{31}$ The selection of the adsorbent/adsorptive working pair mainly depends on the three temperature levels which are dictated by the application. For airconditioning systems, water is a very efficient refrigerant since it has a very large evaporation enthalpy leading to a high amount of heat that can be extracted from the evaporator per adsorption cycle. ${ }^{31}$ As far as thermodynamic aspects are concerned, the most important figure of merit is the loading spread also called the working capacity, i.e the mass of adsorbed water per unit of adsorbent mass. This loading spread depends on the operation conditions of the cycle determined by the three governing temperature levels. Nevertheless, the working capacity measured on an adsorption isotherm at two different relative humidities can be used as a first screening process for adsorbent selection. The methodology for this adsorbent screening based on adsorption isotherm data are described elsewhere. ${ }^{31,}$ 60, 125 Both the thermodynamic and dynamic requirements for designing optimal adsorbents for heat transformation are summarized in Ref. ${ }^{146}$. The evaluation of materials for thermally driven chillers (TDC) or adsorption-based heat pumps (AHP) applications can be realized by measuring isobars at the condenser and evaporator pressures. ${ }^{147}$ For typical values corresponding to practical applications, this window lies between $0.05<\mathrm{p} / \mathrm{p}^{\circ}<0.32$ in which a maximum working fluid exchange has to be reached. ${ }^{31}$ Silica generally displays poor water working capacities (0.2-0.3 $\mathrm{g} / \mathrm{g}$ ). More hydrophilic zeolites and zeotype adsorbents exhibit larger working capacities. However, the increase in hydrophilicity with these materials leads to higher desorption temperatures which often surpass those provided by lowtemperature waste heat or solar collectors.

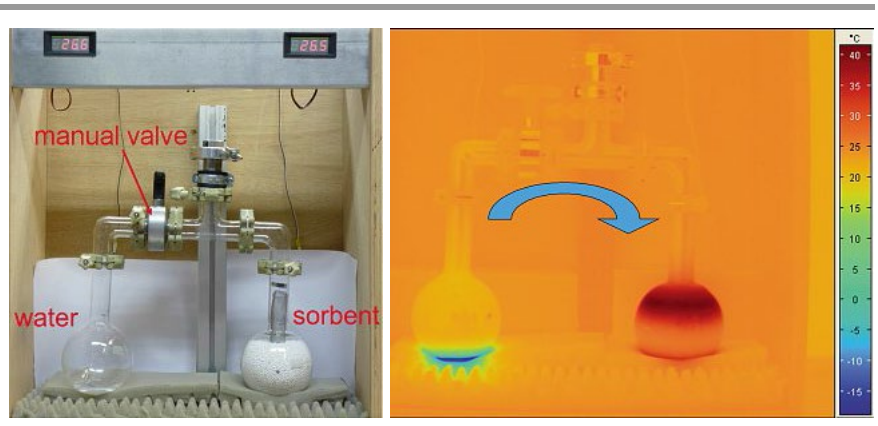

Fig. 24 Experimental setup for the illustration of heat and cold generation in the adsorption step. The left image shows the system before opening the manual valve. The right image shows the data recorded by a thermal camera picture a few minutes after opening the valve. The thermal data indicate the different temperatures in the device: $\sim-5{ }^{\circ} \mathrm{C}$ in the water flask (with ice formation) and $\sim 40$ ${ }^{\circ} \mathrm{C}$ in the adsorbent flask. Reprinted with permission from ref. ${ }^{31}$.

Metal organic frameworks for the applications above are very attractive owing to their tunable water adsorption-desorption properties. MOFs generally display large water uptake, exceeding $1 \mathrm{~g} / \mathrm{g}$ in some cases. Furthermore, the "S"-type adsorption isotherm often found for MOFs makes them appropriate since a very large working capacity can be obtained on a very narrow window of relative pressures. As described in section 2.3 and in Table 1, many MOFs exhibit stepwise adsorption in a pressure range which falls into the relevant windows, that is, at low to medium humidity. Water cycling adsorption/desorption were carried out on various MOF exhibiting type $\mathrm{V}$ adsorption isotherms, Al- and Fe-MIL-100 (Fig 25), ${ }^{93}$ UiO-66 and MIL-125, ${ }^{83}$ MIL-101, ${ }^{60,138}$ functionalised MIL-101138 and post-modified MIL-101.11 The cycling experiments are illustrated in Fig. 25 for Al-MIL-100. Samples were exposed to a humidified gas flow with a partial water vapour pressure of $5.6 \mathrm{kPa}$ using argon as a carrier. The temperature was varied between 40 and $140^{\circ} \mathrm{C}$ for 40 cycles and $5 \mathrm{~h}$ per cycle. Al-MIL-100 is relatively water-stable with, 
however, subsequential losses of water capacities (-6\% after 40 cycles). Interestingly, the degree of crystallinity is enhanced after cycling, which may arise from an additional activation/washing of the pores by the repeated condensation of the adsorbate. ${ }^{74}$ Another example is the Cr-MIL-101- $\mathrm{NH}_{2}$ which shows exceptional performances with high lift $(0.55 \mathrm{~g} / \mathrm{g})$ and an average heat of adsorption of $43 \mathrm{~kJ} / \mathrm{mol}$ over 40 cycles without performance loss. ${ }^{138}$ While the stability of several MOFs after 40 adsorption/desorption cycles makes them promising candidates, short experimental assay are still insufficient for practical applications for heat transformation (commercially available adsorbents are hydrothermally stable after 200,000 and 60,000 cycles). Other possible issues, which might hamper the use of MOFs for heat transformation, include the presence in many cases of adsorption/desorption hystereses and the low temperature lift for heat pump applications.

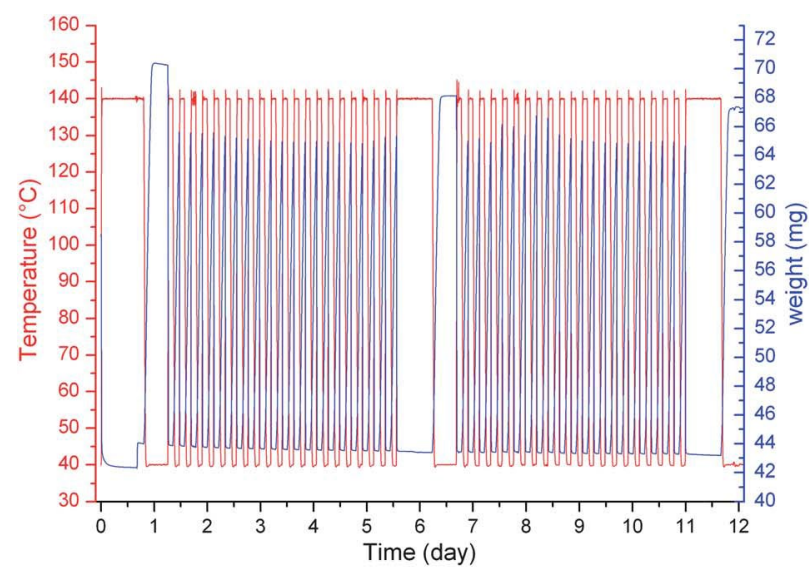

Fig. 25 Temperature profile and load signal of the Al-MIL-100 during cycling experiment acquired at a water vapor pressure $p_{\mathrm{H} 2 \mathrm{O}}=5.6 \mathrm{kPa}$. Reprinted with permission from ref. ${ }^{93}$.

\subsection{Proton conducting MOFs}

Proton exchange membrane fuel cell (PEMFC) is an attractive energy conversion technology that uses clean renewable sources (hydrogen and air) for electricity production. High power densities and low operating temperatures make PEMFCs promising candidates for use in stationary as well as transport and portable applications. ${ }^{148}$ A PEMFC consists of a porous anode and a porous cathode separated by a polymer electrolyte membrane (PEM). Hydrogen is supplied to the anode and is oxidized to produce an electron and a proton. Protons travel to the cathode through the proton exchange membrane. Protons and electrons arriving at the cathode are then combined with oxygen to give water. This creates a current flow through the electric circuit that the fuel cell is powering. The overall performance of the fuel cell in such an architecture is directly affected by the proton conductivity of the PEM.

The state-of-the-art material for PEM is Nafion, which has to be used in its fully hydrated state for good performance. Therefore, the water content of the material critically affects its proton conductivity performance. ${ }^{149,150}$ The hydration state has to be carefully monitored as dehydration leads to membrane drying and, thus, proton conductivity loss. On the other hand, increased water content in the system leads to flooding of electrodes and is extremely detrimental to fuel cell performance. The molecular structure of Nafion is composed of a hydrophobic polyfluorocarbon backbone with hydrophilic ion exchange side chains containing sulfonate groups. Upon hydration, swelling of the polymer occurs and creates a phase separation; hydrophilic pores that contain water are surrounded by the hydrophobic polyfluorocarbon. In the hydrated state, Nafion displays a high proton conductivity (up to $10^{-1} \mathrm{~S} . \mathrm{cm}^{-1}$ at room temperature, $100 \%$ relative humidity). ${ }^{151}$ Another advantage of this material is to be currently commercially available. However, the cost of PEMFC components is high when compared to the cost of traditional systems. The focus of research in this field of materials science is therefore on reducing the cost of PEMs. Another criterion for a useful PEM material is high thermal, hydrolytic, and mechanical stabilities. In the case of Nafion, the glass transition temperature at around $90^{\circ} \mathrm{C}$ limits its thermal stability so that a lot of efforts are devoted to the development of a more robust material for its use as a PEM. New materials should have a strong water uptake, high proton conductivity, low gas permeability, and high stability.

As described in the sections above, MOFs are good candidates for applications involving water adsorption since their crystalline nature allows a precise understanding of the structural changes upon hydration. For these reasons, they have attracted a great deal of attention as PEM materials for PEMFCs. After a brief summary of proton conduction mechanisms and measurement setups, we review below the research progress made in this field.

Proton Conduction mechanisms. The most prominent mechanisms used to explain proton conduction are the "Vehicle mechanism" and "Grotthus hopping". 152, 153 The vehicle mechanism can be described by proton diffusion occurring along with the diffusion of the vehicle (water molecule). Here, counter diffusion of unprotonated water drives transport of the neat proton. This type of proton motion is thus strongly dependent on water diffusion in the media. In the Grotthus mechanism, water transport is not necessary as proton motion occurs through the transfer from one water molecule to the next via hydrogen bonding. The hydration level of the membrane will favour one mechanism over the other. At low relative humidity $(\mathrm{RH})$, there is not enough water molecules to create a hydrogen bond path so that the vehicle mechanism prevails. When the relative humidity increases, channels of continuous hydrogen bond pathways are accessible and protons can migrate by Grotthus hopping. The activation energy for proton conduction through the vehicle mechanism is higher than through a hopping mechanism. Typical reported activation energies are $0.1-0.4 \mathrm{eV}$ for the Grotthus mechanism and $0.5-0.9 \mathrm{eV}$ for the vehicle mechanism.

Proton CONDUCTIVITy IN MOFs. Proton conductivity of MOFs is generally assessed by two-probe AC impedance 
spectroscopy. The microcrystalline powder is pelletized and placed between electrodes to perform measurements on a wide frequency range $\left(10-10^{7} \mathrm{~Hz}\right)$. In addition to the bulk-like intrinsic conductivity of the MOF, the total conductivity can include extrinsic conductivity contributions due to conduction pathways such as grain boundaries. In an ideal study, both the resistive and capacitive components of the intrinsic and extrinsic impedance have to be determined, and an equivalent circuit should be used to fit the data. ${ }^{154}$ However, most of the time, experiments only consist of macroscopic measurements on pellet samples so that the resulting impedance contains both the bulk and grain boundary contributions. To assess the bulk conductivity and to perform anisotropic measurements, impedance spectroscopy on a single crystal is a good yet challenging alternative. Another possible method is to perform measurements on oriented thin films. When such set ups are feasible valuable information on intrinsic and directional conductivities is obtained.

Even if preliminary studies on coordination polymers for proton conduction date back to $1979,{ }^{155}$ noticeable progress has been made only recently in this field. ${ }^{156-158}$ MOFs with proton conductivity can be divided into two conductor types; aqueous and anhydrous. However, only hydrated phases are within the scope of this review so that we emphasize studies providing data on water content. Although sorption isotherms are desirable in order to properly assess water content, relatively few works systematically report these data. In case no water sorption isotherms have been measured, authors rely on thermogravimetric analysis (TGA) for the assessment of water content. It is also worth noting that few authors have considered MOF stability toward hydrolysis, a key feature for PEMFC applications. As mentioned above, MOF proton conductivity was first reported under humid conditions in 1979. In this study, the authors investigated $\mathrm{H}_{2}$ dtoaCu (dtoa = dithiooxamide) whose crystalline structure was unknown. ${ }^{155}$ A moderate proton conductivity of $10^{-6} \mathrm{S.cm}^{-1}$ was reported as well as its dependence on the relative humidity. In more recent studies efforts have been made to obtain water sorption data on MOFs and correlate them with proton conductivity. In what follows, we first review how water triggers conductivity of neutral frameworks. Charged structures (i.e., MOFs containing charged species participating to conduction) is then considered. The development of composite systems such as MOF-based membranes or thin films, closer to real life applications, is then discussed.

NEUTRAL FRAMEWORKS. Hydrophilicity is an important factor to promote water-mediated proton conductivity. Mallick et al. synthesized a series of Ca-BTC frameworks in a variety of solvents. ${ }^{159}$ These as-synthesized phases contain different amounts of water coordinated to the $\mathrm{Ca}^{2+}$ ion as measured by water sorption isotherms. The highest water uptake (6.1 molecules per $\mathrm{Ca}$ ), which was measured for $\mathrm{Ca}-\mathrm{BTC}-\mathrm{H}_{2} \mathrm{O}$, leads to the greatest proton conductivity $\left(1.2 \times 10^{-4}{\mathrm{~S} . \mathrm{cm}^{-1}}\right.$ at room temperature and $98 \% \mathrm{RH}$ ) with a low activation energy of 0.18 $\mathrm{eV}$. The presence of acidic, metal-coordinated $\mathrm{H}_{2} \mathrm{O}$ molecules plays a key-role by facilitating $\mathrm{H}$ bond paths inside the pores.
The importance of the MOF structure on the water uptake was further demonstrated with a series of homochiral MOFs built from $\mathrm{Zn}^{2+}$ and an amino-acid derived linker L- or D-3-methyl-2(pyridin-4-ylmethylamino)butanoic acid. ${ }^{160}$ Among the four chiral compounds that were obtained, $\left[\mathrm{Zn}\left(1-\mathrm{LCl}_{\mathrm{Cl}}(\mathrm{Cl})\right]\left(\mathrm{H}_{2} \mathrm{O}\right)_{2}\right.$ and $[\mathrm{Zn}(\mathrm{d}-\mathrm{L} \mathrm{Cl})(\mathrm{Cl})]\left(\mathrm{H}_{2} \mathrm{O}\right)_{2}$ display proton conductivity of $4.45 \times 10^{-5}$ S.cm ${ }^{-1}$ and $4.42 \times 10^{-5} \mathrm{~S} . \mathrm{cm}^{-1}$ with activation energies of 0.34 and $0.36 \mathrm{eV}$, respectively. This behavior was attributed to the influence of the halogen atom in the structure. Chlorinated structures lead to stronger $\mathrm{H}-\mathrm{Cl}$ bonds compared with their brominated counterpart as well as higher water uptake which allows the formation of a continuous 1D helical water chain inside the pores.

Pore surface decoration is an important factor influencing the conductivity performance of MOFs. In the study of a series of Al-MIL-53-R ( $\left.\mathrm{R}=-\mathrm{H},-\mathrm{NH}_{2},-\mathrm{OH}\right)$ and Fe-MIL-53-COOH, a correlation was found between the $\mathrm{pKa}$ of the $\mathrm{R}$ functionalities and the conducting properties of the MOF. ${ }^{130}$ Water adsorption isotherms and adsorption-induced flexibility are discussed in section 3.2 (Fig. 18). A predominance of the acidity of the functional group over the water uptake capacity was also found. Al-MIL-53-OH adsorbs 3 times more water than Fe-MIL-53$\mathrm{COOH}$ but its conductivity is almost an order of magnitude lower. Room temperature conductivities at $95 \%$ relative humidity ranges from $2.3 \times 10^{-9}$ for $\mathrm{R}=-\mathrm{NH}_{2}$ to $2.0 \times 10^{-6}{\mathrm{~S} . \mathrm{cm}^{-1}}^{-}$ for the more acidic $\mathrm{R}=-\mathrm{COOH}$. Higher conductivity and lower activation energy were obtained upon decreasing the $\mathrm{pKa}$ of the $\mathrm{R}$ substituent. The dominant pathway for proton transport was proposed to be H-bond creation between water, $\mu-\mathrm{OH}$ and $\mathrm{COOH}$ groups in $1 \mathrm{D}$ channels. The pore surface decoration concept was further demonstrated by attaching a sulfonic acid group to $50 \%$ of the aromatic rings in Al-MIL-53; ${ }^{161}$ following this post-synthetic modification, the sulfated material was found to exhibit a higher water uptake than the parent material. Although the RH was not carefully controlled in this study, exceptionally high conductivities were reported at low temperatures (from 20 to $60^{\circ} \mathrm{C}$ ) with values an order of magnitude above those for the best performing MOFs.

Several metal phosphonate-based coordination polymers were also studied for $\mathrm{H}^{+}$conduction. In these compounds the acidic $\mathrm{PO}_{3} \mathrm{H}$ function is generally only partly bonded to the metal so that $\mathrm{H}$ bonds can form with water in the pores. Phosphonatecoordinated compounds are also known to be robust toward hydrolysis so that they are suitable for water-mediated $\mathrm{H}^{+}$ conduction. In the $2 \mathrm{D}$ layered $\mathrm{Zn}$ phosphonate MOF PCMOF-3 $\left(\mathrm{Zn}_{3}(\mathrm{~L})\left(\mathrm{H}_{2} \mathrm{O}\right)_{2} \cdot 2 \mathrm{H}_{2} \mathrm{O}\right.$ with $\mathrm{L}=1,3,5$-benzenetriphosphonate), ${ }^{162}$ ordered chains of water molecules were observed in the interlayer porosity by X-ray diffraction. $\mathrm{H}$ bond transfer was monitored by solid state NMR with ${ }^{1} \mathrm{H}$ or ${ }^{2} \mathrm{H}$ isotopes. Proton mobility was demonstrated down to temperatures as low as $-20^{\circ} \mathrm{C}$. The rather low $\mathrm{H}^{+}$conductivity of $3.5 \times 10^{-5} \mathrm{~S} . \mathrm{cm}^{-1}$ was attributed to grain boundary constraints while the low activation energy of $0.17 \mathrm{eV}$ was explained by a high proton mobility. The same benzenetriphosphonate ligand was later used for an isomorphous replacement in the 3D trisodium,4,6-trihydroxy$1,3,5$-trisulfonate benzene polymer $\beta$-PCMOF- $2 .{ }^{163}$ In this case, 
a third of the linkers were substituted while the overall crystalline structure was maintained. As a result, the pores were partially lined with acidic hydrogen phosphonate groups and the $\mathrm{H}^{+}$ conductivity was enhanced by a factor 16 along with a decrease in the activation energy. The same group reported a 3D PCMOF$5^{164}$ with molecular formula $\left[\mathrm{La}\left(\mathrm{H}_{5} \mathrm{~L}\right)\left(\mathrm{H}_{2} \mathrm{O}\right)_{4}\right](\mathrm{L}=1,2,4,5-$ tetrakisphosphonomethylbenzene). A diprotic phosphonic acid group was left uncoordinated in this structure (Fig. 26), which allows $1 \mathrm{D}$ H-bonding in the highly acidic channels. A noticeable conductivity of $1.3 \times 10^{-3} \mathrm{~S}^{-\mathrm{cm}^{-1}}$ (room temperature, $\mathrm{RH}=98 \%$ ) and a low activation energy of $0.16 \mathrm{eV}$ were reported. Using PXRD, the compound structure was demonstrated to remain intact after 7 days in boiling water as well as after impedance spectroscopy measurements.

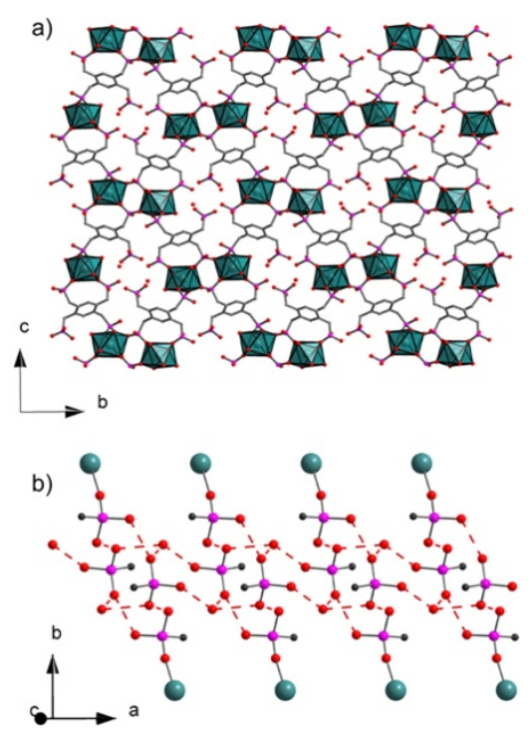

Fig. 26 (a) Structure of PCMOF-5 as viewed down the $a$-axis. Free phosphonic acid groups and uncoordinated water molecules are located in each pore. (b) View showing the one-dimensional hydrogen-bonding array formed between phosphonic acid groups and free water molecules in the direction of the $a$-axis. Reprinted with permission from ref. ${ }^{163}$.

Another La phosphonate $\mathrm{La}\left(\mathrm{H}_{5} \mathrm{DTMP}\right) \cdot 7 \mathrm{H}_{2} \mathrm{O}$ was obtained by Cabeza et al. from $\mathrm{La}^{3+}$ and $\mathrm{H}_{8}$ DTMP $\left(\mathrm{H}_{8} \mathrm{DTMP}=\right.$ hexamethylenediamine-N,N,N',N'-tetrakis(methylenephosphonicacid). ${ }^{165}$ This microporous structure possesses $1 \mathrm{D}$ channels that are filled with $\mathrm{H}_{2} \mathrm{O}$ molecules. A similar conductivity was measured $\left(8 \times 10^{-3}{\left.\mathrm{~S} . \mathrm{cm}^{-1}\right)}\right.$ with an activation energy of $0.25 \mathrm{eV}$ in $98 \% \mathrm{RH}$ at room temperature. This work was further extended to the synthesis of a microporous $3 \mathrm{D}$ pillared structure from $\mathrm{Mg}^{2+}$ and the isomeric $\mathrm{H}_{8} \mathrm{ODTMP}$ ligand ( $\mathrm{H}_{8} \mathrm{ODTMP}=$ octamethylenediamine-N,N,N',N'-tetrakis(methylenephosphonic acid) which leads to a $3 \mathrm{D}$ pillared structure when used with $\mathrm{Mg}^{2+}$ metal centre. ${ }^{166}$ The presence of $\mathrm{POH}$ groups pointing towards the channels filled with water allows proton conductivity. The $\mathrm{MgH}_{6} \mathrm{ODTMP} \cdot 6 \mathrm{H}_{2} \mathrm{O}$ compound showed a high proton

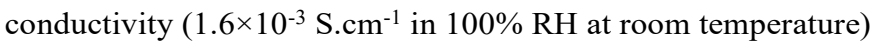
and an activation energy of $0.31 \mathrm{eV}$.

Casciola et al. reported a flexible zirconium tetraphosphonate framework that underwent a phase transition upon thermal treatment and successive rehydration. ${ }^{167}$
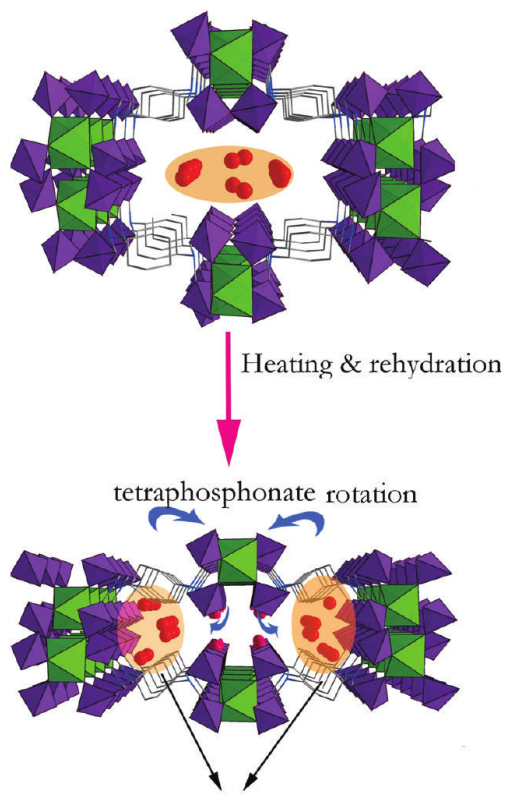

New position of water molecules

Fig. 27 Rotation of the tetraphosphonic groups after heating and new position of the water molecules. Reprinted with permission from ref. ${ }^{167}$.

The two phases shown in Fig. 27 were named 1_lp@H ("lp" stands for large pores) and 1_np@H ("np" stands for narrow pores). Impedance spectroscopy measurements for this system showed that the bulk conductivity was an order of magnitude higher for the large pore phase than for the narrow pore phase. A slightly higher water uptake (5.5 versus 4.5 molecules per formula unit), as determined from powder structural data, was proposed to explain this result. The difference of water location inside the pores leads to shorter H-bonds for 1_lp@H which provide two possible paths for proton hoping. Both materials were checked for structural integrity after impedance spectroscopy; no phase transition or deterioration was observed during the measurements.

CHARGED FRAMEWORKS. The electrical neutrality of charged frameworks is insured by the presence of counterions inside the pores. If protic counterions are used, they can also act as proton carriers. In water-mediated conduction the hydrophilicity of the charged ion can directly impact the water uptake capacity and hence the proton conductivity. In the series of the $2 \mathrm{D}$ oxalatebridged layered MOFs $\left[\mathrm{NR}_{3}\left(\mathrm{CH}_{2} \mathrm{COOH}\right)\right]\left[\mathrm{MCr}(\mathrm{ox})_{3}\right] \cdot \mathrm{nH}_{2} \mathrm{O}(\mathrm{R}$ $=-\mathrm{Me}$, $-\mathrm{Et}$, or $-n-\mathrm{Bu}$, and $\mathrm{M}=\mathrm{Mn}$ or $\mathrm{Fe})$, the charge compensating $\left[\mathrm{NR}_{3}\left(\mathrm{CH}_{2} \mathrm{COOH}\right)\right]^{+}$ammonium can be exchanged, which affects the hydrophilicity of the MOF material. ${ }^{20}$ In this system, the hydrophilicity of the compound decreases with increasing the size of the $\mathrm{R}$ substituent. As expected, the highest water uptake was measured for the most hydrophilic Me-FeCr sample (22\% weight) even in moderate RH conditions. The highest conductivity, $0.8 \times 10^{-4} \mathrm{~S} . \mathrm{cm}^{-1}$, was observed at room temperature for a relative humidity $65 \%$ (Fig. 28). 


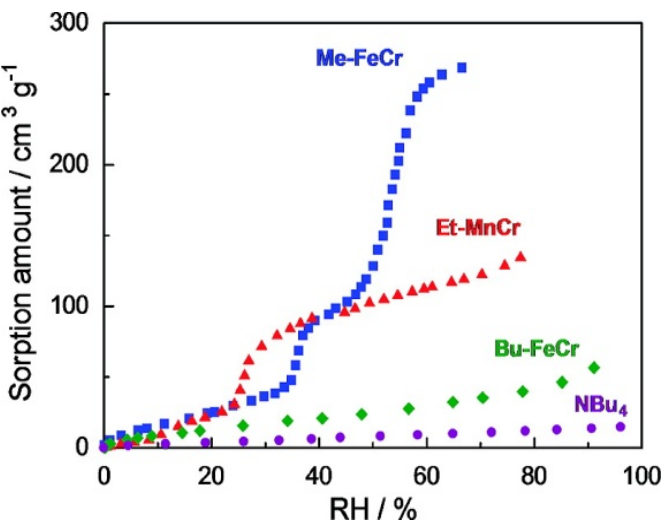

Fig. 28 Water vapor adsorption isotherms for different MOFs at 298K. The blue, red, green, and purple symbols correspond to $\mathrm{Me}-\mathrm{FeCr}$, Et-FeCr, Bu-FeCr, and NBu4, respectively. Reprinted with permission from ref. ${ }^{20}$.

A similar metal-oxalate compound $\left(\mathrm{NH}_{4}\right)_{4}\left[\mathrm{MnCr}_{2}(\mathrm{ox})_{6}\right] \cdot 4$ $\mathrm{H}_{2} \mathrm{O}$ was reported by Verdaguer et al. ${ }^{168}$ This $3 \mathrm{D}$ framework exhibits chirality which arises from the helical $\left[\mathrm{Cr}(\mathrm{ox})_{3}\right]^{3-}$ moieties. The structural data also show that water molecules and ammonium cations are hosted inside the pores. Single crystal Xray diffraction provides evidence of a conductive pathway formed by hydrogen bonding between the framework oxygen from the oxalate linkers, the water molecules, and the ammonium cations. The conductivity of this compound significantly depends on the humidity; the high conductivity of $1.110^{-3}{\mathrm{~S} . \mathrm{cm}^{-}}^{-}$ ${ }^{1}$ at $295 \mathrm{~K}$ and $96 \% \mathrm{RH}$ was attributed to the proximity between the protic ion $\mathrm{NH}_{4}{ }^{+}$, the water molecules, and the framework oxygen atoms. The $2 \mathrm{D}$ layered framework $\left(\mathrm{NH}_{4}\right)_{2}(\mathrm{adp})-$ $\left[\mathrm{Zn}_{2}(\mathrm{ox})_{3}\right] \cdot 3 \mathrm{H}_{2} \mathrm{O}(\mathrm{adp}=$ adipic acid, ox $=$ oxalate $)$ is made up of infinite layers of anionic $\left[\mathrm{Zn}_{2}(\mathrm{ox})_{3}\right]^{2-}$ polymer. Adipic acid in the interlayer space is located in the vicinity of the ammonium ions and water molecules. ${ }^{169}$ This spatial arrangement constitutes a hydrogen bond pathway with high proton conductivity of $8 \cdot 10^{-3}$ ${\mathrm{S} . \mathrm{cm}^{-1}}^{-}$at room temperature and $98 \% \mathrm{RH}$. The high activation energy reported for this process suggests that the conduction mechanism rather pertains to water or ammonium diffusion than a hopping mechanism. Another way to introduce charged proton carriers into the structure of MOFs is to use an electrically charged spacer. For example, highly acidic hydrogen in imidazolium ions, which are known to favour proton conductivity, have been used to promote anhydrous proton conductivity in MOFs. ${ }^{170}$ In the case of $\left[\left\{\left(\mathrm{Zn}_{0.25}\right)_{8}(\mathrm{O})\right\} \mathrm{Zn}_{6}(\mathrm{~L})_{12}\left(\mathrm{H}_{2} \mathrm{O}\right)_{29}(\mathrm{DMF})_{69}\left(\mathrm{NO}_{3}\right)_{2}\right] \mathrm{n} \quad\left(\mathrm{H}_{2} \mathrm{~L}=1,3-\right.$ bis(4-carboxyphenyl)imidazolium), the resulting MOF is built using a positively charged $\mathrm{H}_{2} \mathrm{~L}$ ligand. The charge is compensated by the presence of nitrate anions in the structure (Fig. 29). ${ }^{171}$ This porous compound has two types of channels, both lined with acidic methylene protons from the linker. Conductivity in this compound is clearly correlated with the water uptake by the framework; at least 5 adsorbed water molecules per formula unit are needed to reach high proton conductivity. Conductivities as high as $2.3 \times 10^{-3}{\mathrm{~S} . \mathrm{cm}^{-1}}$ were measured for $95 \% \mathrm{RH}$ at room temperature.
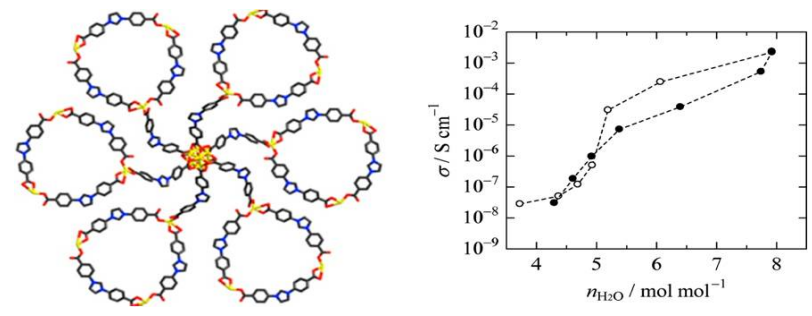

Fig. 29 (left) Six metallomacrocycles connected to the core $\left\{\mathrm{Zn}_{8} \mathrm{O}\right\}$ cluster. (right) Proton conductivity dependence on water uptake. Conductivity was measured with an increase (filled circles) and a decrease (open circles) of the water content. Reprinted with permission from ref. ${ }^{171}$.

Post-synthetic introduction of charged species has also been used as a way to enhance ionic conductivity in the pores of MOF materials. Calcium squarate $\left[\mathrm{Ca}\left(\mathrm{C}_{4} \mathrm{O}_{4}\right)\left(\mathrm{H}_{2} \mathrm{O}\right)\right]$ was reported to be a microporous compound with $1 \mathrm{D}$ pores of a diameter $D=3.4 \AA$ (Fig. 30). ${ }^{172}$ The mobility of water molecules in the parent MOF was found to be very low as water is coordinated to the metallic ion. An enhancement of water mobility was achieved by post synthetic solid phase reaction with $\mathrm{LiCl}$. Single crystal diffraction shows that some coordinated water molecules are replaced by $\mathrm{Cl}^{-}$ions which enable the $\mathrm{Li}^{+}$ions to migrate in the channels. Homogeneity of the functionalisation was confirmed by EDX. For the resulting structure, a formula of $\left[\mathrm{Ca}\left(\mathrm{C}_{4} \mathrm{O}_{4}\right)(\mathrm{Cl})_{0.5}\left(\mathrm{H}_{2} \mathrm{O}\right)_{0.5}\right]\left(\mathrm{Li}_{0.5}\right)\left(\mathrm{H}_{2} \mathrm{O}\right)_{3.5}$ was proposed at $40 \%$ $\mathrm{RH}$. The latter compound adsorbs more water than its parent material, and the adsorption isotherms exhibit a hysteresis loop when adsorption/desorption cycles are performed. As shown in Fig. 31, a remarkable conductivity increase by a factor $10^{6}$ (with respect to the parent MOF) was found for the modified compound. The conductivity remains high upon decreasing the $\mathrm{RH}$ from 40 to $10 \%$ due to the hysteresis in the water release process. ${ }^{1} \mathrm{H}$ and ${ }^{7} \mathrm{Li}$ solid state NMR was used to measure the diffusion coefficients in the pores; both ionic species were found to be highly mobile. A membrane electrode was also assembled, and an open circuit voltage of $1 \mathrm{~V}$ was retained for 2 hours.

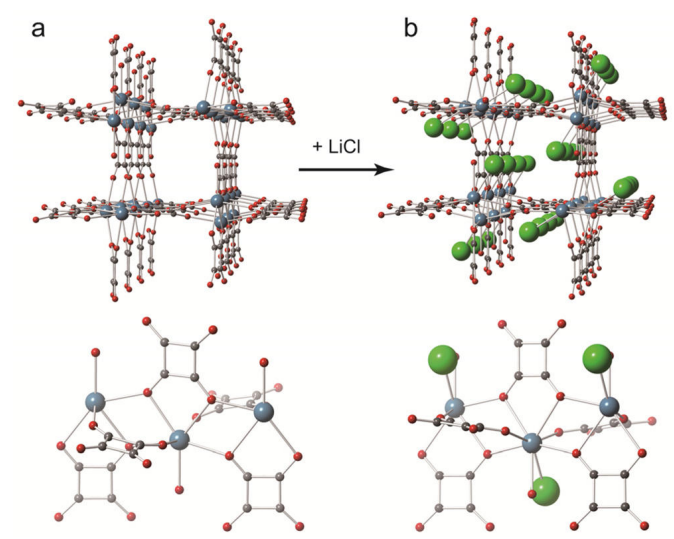

Fig. 30 Crystal structures: (a) CaMOF $\supset x \mathrm{H}_{2} \mathrm{O}$ at $10{ }^{\circ} \mathrm{C}$ and (b) $\mathrm{CaMOF} \cdot \mathrm{LiCl} \supset x \mathrm{H}_{2} \mathrm{O}$ at $-50^{\circ} \mathrm{C}$ along the $c$-axis (top) and the coordination environments around the $\mathrm{Ca} 2+$ ions (bottom). Non-coordinating water molecules are omitted for the sake of clarity. Blue, gray, red, and green are $\mathrm{Ca}^{2+}$, carbon, oxygen, and chlorine respectively. For chlorine, one disordered position is displayed. Reprinted with permission from ref. ${ }^{172}$. 

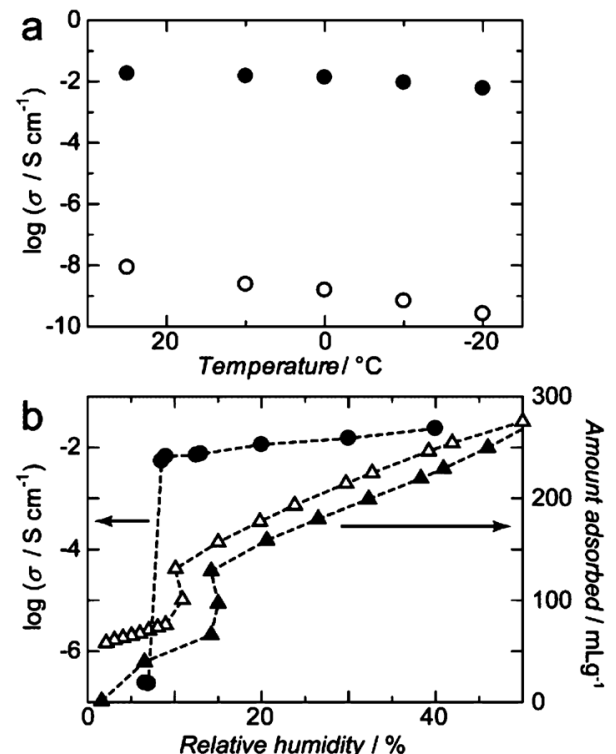

Fig. 31 (a) Arrhenius plots of ion conductivity for CaMOF $\supset \mathrm{xH}_{2} \mathrm{O}$ (open circles) and CaMOF-LiCl $\supset \mathrm{xH}_{2} \mathrm{O}$ (filled circles) at $\mathrm{RH}=40 \%$. (b) Humidity dependency of ion conductivity for CaMOF. LiCl $\supset \mathrm{xH}_{2} \mathrm{O}$ at $25{ }^{\circ} \mathrm{C}$ (filled circles). The $\mathrm{H}_{2} \mathrm{O}$ adsorption (filled triangles) and desorption (open triangles) isotherms of 1 - $\mathrm{LiCl}$ at $25^{\circ} \mathrm{C}$. Reprinted with permission from ref. ${ }^{172}$.

Composite systems. As mentioned earlier, impedance measurements on bulk MOFs can be challenging to interpret. The bulk and grain boundary contributions are complex and uncertainty remains as to whether the pores or the external surface act as pathways for proton transfer. One strategy to avoid grain boundary contributions is to perform measurements on single crystals. However, this technique is not always possible due to limitations in growing large enough crystals. Another possibility, which was used by Kitagawa and co-workers, is to grow a nanofilm of a porphyrinic MOF ( $\mathrm{Cu}-\mathrm{TCPP})$ using a modular assembly approach. ${ }^{173}$ The oriented thin film allows anisotropic impedance measurements in order to determine the nature of conduction pathways. This also increases the efficiency of devices and provides a step towards real life applications. A 2D MOF structure was oriented with the $a, b$ directions in the plane of the films and 1D pores, which run along the $c$-axis, aligned out of plane (Fig. 32). Water sorption measurements show that adsorption does not occur inside the pores but on the surface of the mesopores between nanosheets. X-ray diffraction in various $\mathrm{RH}$ conditions shows no structural change upon hydration. When a $350 \mathrm{~nm}$ thick nanofilm is deposited between two electrodes for impedance measurements, the conductivity is found to be strongly dependent on RH. A high conductivity value of $3.9 \times 10^{-3}{\mathrm{~S} . \mathrm{cm}^{-1}}^{-1}$ at $98 \% \mathrm{RH}$ was attributed to a sharp increase in the water adsorbed amount upon capillary condensation at $\mathrm{RH}$ $>90 \%$. Given that this condensation takes place on the surface of the nanosheets and not inside the nanopores, the conductivity pathway is thought to take place through dangling water and carboxylate groups at the MOF surface and through the condensed water molecules.

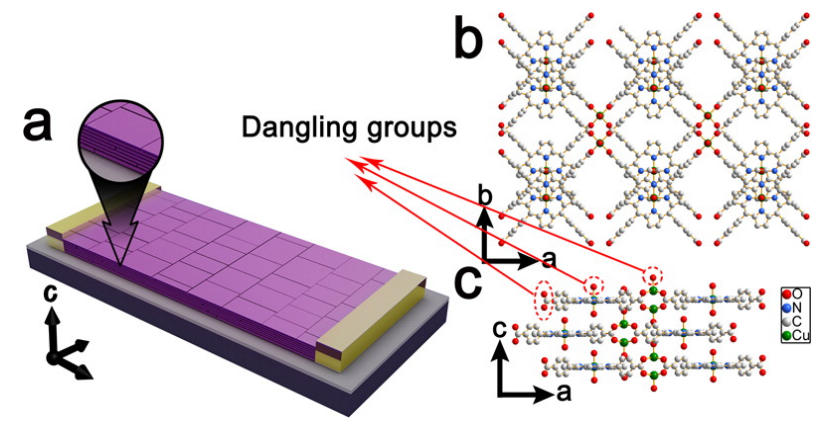

Fig. 32 Schematic representation of a MOF nanofilm for electrical measurement (a) and the modeled crystal structure of the MOF nanofilm (b and c). All H atoms are omitted for the sake of clarity. Reprinted with permission from ref. ${ }^{173}$.

In a similar approach, Ti-MIL-125- $\mathrm{NH}_{2}$ nanoparticles were deposited on interdigitated electrodes. ${ }^{84}$ The influence of $\mathrm{RH}$ on the impedance response was studied to assess the performance of such architecture for humidity sensor device. Although water sorption was not quantitatively studied in this work, a sorption isotherm for bulk Ti-MIL-125- $\mathrm{NH}_{2}$ was reported elsewhere. ${ }^{83}$ The impedance signal at low frequencies is highly dependent on the relative humidity, which demonstrates that the film can be used as a humidity sensor. Recovery of the impedance signal in different RH conditions was also checked by probing adsorption/desorption cycle (only a very narrow hysteresis was obtained). Fast response times were found when the device is taken from 11 to $95 \% \mathrm{RH}$, which demonstrates the viability of the concept.

Another emerging approach in this field consists of using MOFs to build a polymer composite membrane. A 2D layered chiral $\mathrm{Ca}^{2+}$ MOF displaying proton conductivity in a humid atmosphere was embedded in the highly hydroscopic PVP (polyvinylpyrrolidone) polymer matrix by spin coating. ${ }^{174} \mathrm{Sub}-$ micron rods of MOF were used to increase interface contact in this purely physical mixture. This study suggested that the PVP polymer enhances the humidification properties of the composite and, hence, facilitates $\mathrm{H}^{+}$transport pathways in the MOF. The conductivity of the composite at $50 \%$ weight MOF loading was found to be greater than that for the pure MOF. The authors in ref. 174 also highlighted the cost effectiveness of such a membrane compared to Nafion although the performance of the latter remains better at the moment. Another approach was to strongly attach through chemical bonding Fe-MIL-101- $\mathrm{NH}_{2}$ to the SPPO (sulfonated poly-2,6-dimethyl-1,4-phenylene oxide) polymer. ${ }^{175}$ Notably, SPPO has been already widely envisaged for fuel cell membranes. ${ }^{176}$ To design the composite system, the sulfonate groups of SPPO were reacted with $\mathrm{SOCl}_{2}$ affording sulfonyl chloride $\mathrm{SO}_{2} \mathrm{Cl}$ groups in the polymer. These were reacted with amine functions from the MOF leading to the sulfonamide forming a bridge between the MOF and SPPO. An optimal MOF content for proton conductivity was found to be $6 \%$ weight. A high conductivity of $0.1 \mathrm{~S}^{\mathrm{c}} \mathrm{cm}^{-1}$ was achieved with this loading at $298 \mathrm{~K}$ and $98 \% \mathrm{RH}$. This value is much higher than that of the pure MOF and slightly higher than for the pure SPPO. The conductivity promotion was considered to be due to the presence of the highly acidic sulfonamide groups along with 
the unsaturated $\mathrm{Fe}$ (III) centres that are able to increase the acidity of water molecules by modifying their coordination.

The examples listed above show that MOFs can be used to reach high water-triggered proton conductivities needed for PEM materials. Phosphonate based frameworks are known for their hydrostability and are therefore attractive candidates. Studies of water adsorption in these materials should be explored in more details. MOFs exhibiting hysteretic water sorption isotherms are also interesting materials for PEM applications as they would allow performance stability in a more flexible $\mathrm{RH}$ domain than Nafion. The recent development of MOF-based composite systems is a promising step towards real-life applications. Yet, the stability under working conditions needs to be further explored before their use in fuel cell applications becomes viable.

Table 2: MOF conductivity data in hydrated conditions

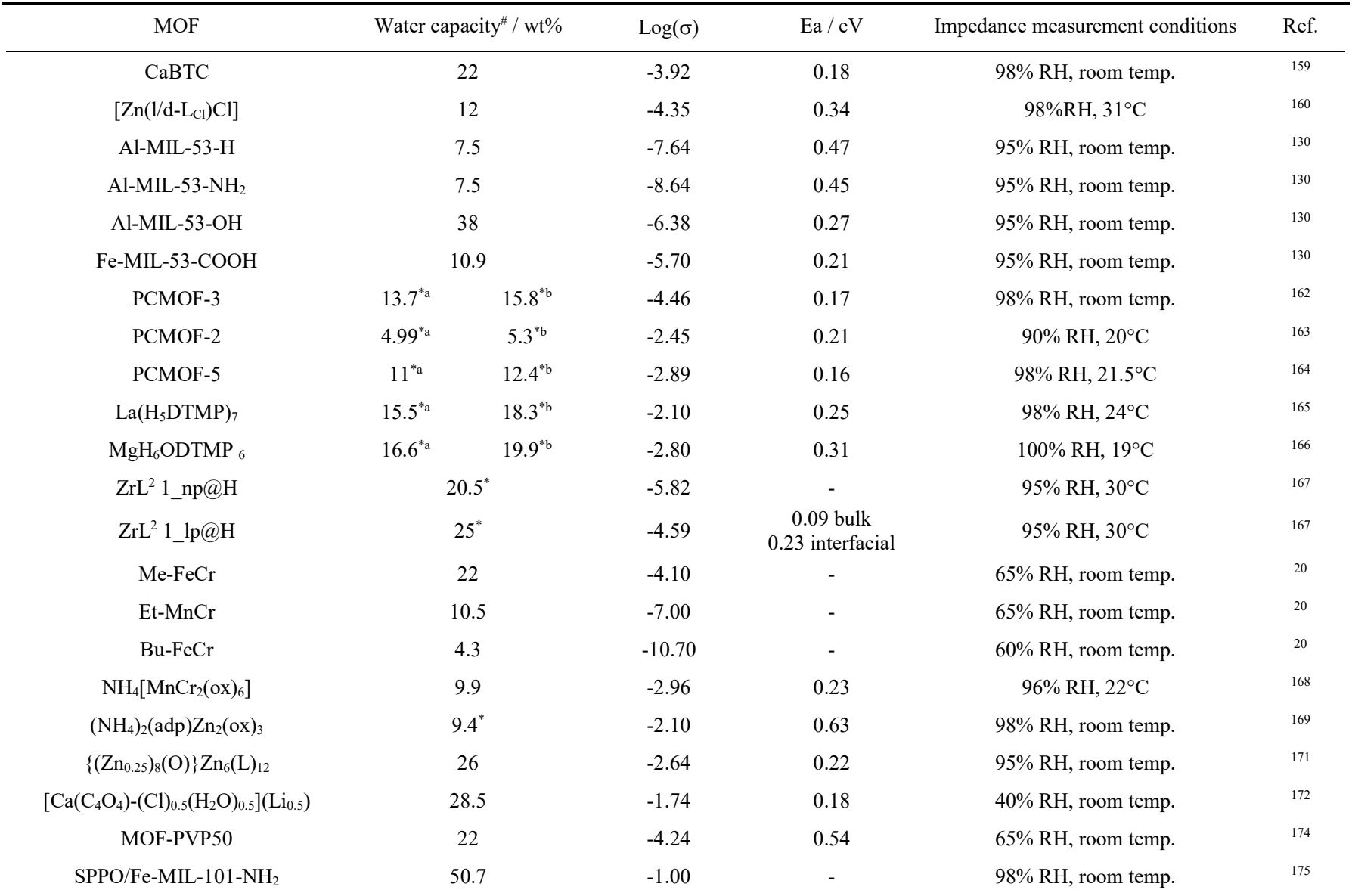

\#: water capacity at the RH of the impedance data; *: water uptake was not assessed by volumetric or gravimetric analysis but using TGA, ICP or crystallographic data; ${ }^{* a}$ : raw TGA data; $*$ b: calculated water weight percent for the anhydrous material.

\section{Conclusions and perspectives}

At the exception of heat-pump and thermally driven adsoroption chillers for which water stable MOF materials may exist, most applications in which MOFs are promising candidates deal with much more demanding media such as acid or basic media. The quest of more stable MOFs, while keeping a very large and controlled porosity, is therefore a corner stone for the development of industrial applications. Among the different approaches for the design of more stable MOFs, the use of cation with high valence and coordination number such as $\mathrm{Zr}^{4+}$, the synthesis of porous solids with infinite inorganic chains such as in MIL-53, and the use of azolate linkers are very interesting directions to explore.

A large variety of stable MOFs exhibits very attractive water adsorption profiles for heat-pump and chiller applications. Obviously, MOFs offer infinite solutions for the design of efficient adsorbents thanks to their versatility in terms of pore size and surface chemistry. The challenge lies in the design of porous solids which adsorb reversibly a very large amount of water within a narrow relative humidity window. Beyond long term stability issues, adsorption kinetics, ${ }^{142}$ heat conductivity, and shaping/processing are key aspects for the overall efficiency of the system which need to be investigated in depth. Similarly, shaping of MOF as chemically and mechanically stable thin films is also a prerequisite for proton conducting applications.

\section{Acknowledgements}

This work was partially supported by a grant "NEEDS Nucléaire, Energie, Environnement, Déchets et Société" in the framework of the project OCTAPPOM. We thank Dr FrançoisXavier Coudert for fruitful discussions.

\section{Notes and references}


${ }^{a}$ IRCELYON, Université Lyon 1, CNRS, UMR 5256, 2 avenue Albert Einstein, F-69626 Villeurbanne, France.

E-mail: david.farrusseng@ircelyon.univ-lyon1.fr; Fax: +33 4724453 99; Tel: +33472445365

${ }^{b}$ Laboratoire des Multimatériaux et Interfaces, Université Lyon 1, UMR 5615, 43 Boulevard du 11 Novembre 1918, F-69622 Villeurbanne, France

${ }^{c}$ MultiScale Material Science for Energy and Environment, CNRS/MIT, UMI

3466, Massachusetts Institute of Technology, 77 Massachusetts Avenue, Cambridge MA 02139, USA

${ }^{d}$ Department of Civil and Environmental Engineering, Massachusetts Institute of Technology, 77 Massachusetts Avenue, Cambridge MA 02139, USA

1 H. Li, M. Eddaoudi, M. O'Keeffe and O. M. Yaghi, Nature, 1999, 402, 276.

2 S. S. Y. Chui, S. M. F. Lo, J. P. H. Charmant, A. G. Orpen and I. D. Williams, Science, 1999, 283, 1148.

3 L. M. Huang, H. T. Wang, J. X. Chen, Z. B. Wang, J. Y. Sun, D. Y. Zhao and Y. S. Yan, Microporous Mesoporous Mater., 2003, 58, 105.

4 S. S. Kaye, A. Dailly, O. M. Yaghi and J. R. Long, J. Am. Chem. Soc., 2007, 129, 14176.

5 P. M. Schoenecker, C. G. Carson, H. Jasuja, C. J. J. Flemming and K. S. Walton, Ind. Eng. Chem. Res., 2012, 51, 6513.

6 S. R. Miller, D. Heurtaux, T. Baati, P. Horcajada, J.-M. Greneche and C. Serre, Chem. Commun., 2010, 46, 4526.

7 W. J. Rieter, K. M. Pott, K. M. L. Taylor and W. B. Lin, J. Am. Chem. Soc., 2008, 130, 11584.

8 W. J. Rieter, K. M. L. Taylor, H. Y. An, W. L. Lin and W. B. Lin, J. Am. Chem. Soc., 2006, 128, 9024.

9 K. M. L. Taylor, A. Jin and W. B. Lin, Angew. Chem. Int. Ed., 2008, 47, 7722 .

10 K. M. L. Taylor, W. J. Rieter and W. B. Lin, J. Am. Chem. Soc., 2008, 130, 14358.

11 L. Guillemot, T. Biben, A. Galarneau, G. Vigier and E. Charlaix, Proc. Natl. Acad. Sci. U. S. A., 2012, 109, 19557.

12 F. Cailliez, M. Trzpit, M. Soulard, I. Demachy, A. Boutin, J. Patarin and A. H. Fuchs, Phys. Chem. Chem. Phys., 2008, 10, 4817.

13 Y. Liu, J. Liu, Y. S. Lin and M. Chang, J. Phys. Chem. C, 2014, 118, 6744.

14 A. C. Kizzie, A. G. Wong-Foy and A. J. Matzger, Langmuir, 2011, 27, 6368.

15 J. Liu, P. K. Thallapally, B. P. McGrail, D. R. Brown and J. Liu, Chem. Soc. Rev., 2012, 41, 2308.

16 J. Liu, J. Tian, P. K. Thallapally and B. P. McGrail, J. Phys. Chem. C, 2012, 116, 9575.

17 E. Soubeyrand-Lenoir, C. Vagner, J. W. Yoon, P. Bazin, F. Ragon, Y. K. Hwang, C. Serre, J.-S. Chang and P. L. Llewellyn, J. Am. Chem. Soc., 2012, 134, 10174.

18 A. O. Yazaydin, A. I. Benin, S. A. Faheem, P. Jakubczak, J. J. Low, R. R. Willis and R. Q. Snurr, Chem. Mater., 2009, 21, 1425.

19 Y. F. Chen, R. Babarao, S. I. Sandler and J. W. Jiang, Langmuir, 2010, 26, 8743.

20 M. Sadakiyo, H. Okawa, A. Shigematsu, M. Ohba, T. Yamada and H. Kitagawa, J. Am. Chem. Soc., 2012, 134, 5472.

21 P. Guo, A. G. Wong-Foy and A. J. Matzger, Langmuir, 2014, 30, 1921.

22 N. A. Khan, B. K. Jung, Z. Hasan and S. H. Jhung, J. Hazard. Mater., 2014, http://dx.doi.org/10.1016/j.jhazmat.2014.03.047.

23 L. Xie, D. Liu, H. Huang, Q. Yang and C. Zhong, Chem. Eng. J., 2014, 246, 142.
24 H. Furukawa, F. Gandara, Y.-B. Zhang, J. Jiang, W. L. Queen, M. R. Hudson and O. M. Yaghi, J. Am. Chem. Soc., 2014, 136, 4369.

25 P. Kuesgens, M. Rose, I. Senkovska, H. Froede, A. Henschel, S. Siegle and S. Kaskel, Microporous Mesoporous Mater., 2009, 120, 325.

26 H. Deng, C. J. Doonan, H. Furukawa, R. B. Ferreira, J. Towne, C. B. Knobler, B. Wang and O. M. Yaghi, Science, 2010, 327, 846.

27 M. Eddaoudi, J. Kim, N. Rosi, D. Vodak, J. Wachter, M. O'Keeffe and O. M. Yaghi, Science, 2002, 295, 469.

28 J. L. C. Rowsell and O. M. Yaghi, J. Am. Chem. Soc., 2006, 128, 1304.

29 J. H. Im, N. Ko, S. J. Yang, H. J. Park, J. Kim and C. R. Park, New J. Chem., 2014, DOI: 10.1039/C4NJ00138A.

30 J. J. Low, A. I. Benin, P. Jakubczak, J. F. Abrahamian, S. A. Faheem and R. R. Willis, J. Am. Chem. Soc., 2009, 131, 15834.

31 C. Janiak and S. K. Henninger, Chimia, 2013, 67, 419.

32 J. B. DeCoste, G. W. Peterson, H. Jasuja, T. G. Glover, Y.-g. Huang and K. S. Walton, J. Mater. Chem. A, 2013, 1, 5642.

33 P. D. C. Dietzel, B. Panella, M. Hirscher, R. Blom and H. Fjellvag, Chem. Commun., 2006, 959.

34 K. A. Cychosz and A. J. Matzger, Langmuir, 2010, 26, 17198.

35 Z.-Y. Gu, G. Wang and X.-P. Yan, Anal. Chem., 2010, 82, 1365.

36 S. Hausdorf, J. Wagler, R. Mossig and F. O. R. L. Mertens, Journal of Physical Chemistry A, 2008, 112, 7567.

37 J. A. Greathouse and M. D. Allendorf, J. Am. Chem. Soc., 2006, 128, 10678.

38 S. Aguado, J. Canivet, Y. Schuurman and D. Farrusseng, J. Catal., 2011, 284, 207.

39 K. S. Park, Z. Ni, A. P. Cote, J. Y. Choi, R. Huang, F. J. Uribe-Romo, H. K. Chae, M. O'Keeffe and O. M. Yaghi, Proc. Natl. Acad. Sci. U. S. A., 2006, 103, 10186 .

40 I. Bezverkhyy, G. Ortiz, G. Chaplais, C. Marichal, G. Weber and J.-P. Bellat, Microporous Mesoporous Mater., 2014, 183, 156.

41 D. Feng, Z.-Y. Gu, J.-R. Li, H.-L. Jiang, Z. Wei and H.-C. Zhou, Angew. Chem. Int. Ed., 2012, 51, 10307.

42 D. Feng, W.-C. Chung, Z. Wei, Z.-Y. Gu, H.-L. Jiang, Y.-P. Chen, D. J. Darensbourg and H.-C. Zhou, J. Am. Chem. Soc., 2013, 135, 17105.

43 H.-L. Jiang, D. Feng, K. Wang, Z.-Y. Gu, Z. Wei, Y.-P. Chen and H.C. Zhou, J. Am. Chem. Soc., 2013, 135, 13934.

44 C. Volkringer and S. M. Cohen, Angew. Chem. Int. Ed., 2010, 49, 4644.

45 X. Liu, Y. Li, Y. Ban, Y. Peng, H. Jin, H. Bux, L. Xu, J. Caro and W. Yang, Chem. Commun., 2013, 49, 9140.

46 M. Kandiah, M. H. Nilsen, S. Usseglio, S. Jakobsen, U. Olsbye, M. Tilset, C. Larabi, E. A. Quadrelli, F. Bonino and K. P. Lillerud, Chem. Mater., 2010, 22, 6632.

47 D. Cunha, M. Ben Yahia, S. Hall, S. R. Miller, H. Chevreau, E. Elkaim, G. Maurin, P. Horcajada and C. Serre, Chem. Mater., 2013, 25, 2767.

48 F. Vermoortele, M. Vandichel, B. Van de Voorde, R. Ameloot, M. Waroquier, V. Van Speybroeck and D. E. De Vos, Angew. Chem. Int. Ed., 2011, 51, 4887.

49 M. Kim, J. F. Cahill, H. Fei, K. A. Prather and S. M. Cohen, J. Am. Chem. Soc., 2012, 134, 18082.

50 S. Pullen, H. Fei, A. Orthaber, S. M. Cohen and S. Ott, J. Am. Chem. Soc., 2013, 135, 16997.

51 M. Savonnet, D. Bazer-Bachi, N. Bats, J. Perez-Pellitero, E. Jeanneau, V. Lecocq, C. Pinel and D. Farrusseng, J. Am. Chem. Soc., 2010, 132, 4518 . 
52 H. J. Choi, M. Dinca, A. Dailly and J. R. Long, Energy Environ. Sci., $2010,3,117$.

53 H. Jasuja, Y.-g. Huang and K. S. Walton, Langmuir, 2012, 28, 16874.

54 H. Jasuja, N. C. Burtch, Y.-g. Huang, Y. Cai and K. S. Walton, Langmuir, 2013, 29, 633.

55 D. Ma, Y. Li and Z. Li, Chem. Commun., 2011, 47, 7377.

56 T. Wu, L. Shen, M. Luebbers, C. Hu, Q. Chen, Z. Ni and R. I. Masel, Chem. Commun., 2010, 46, 6120.

57 J. M. Taylor, R. Vaidhyanathan, S. S. Iremonger and G. K. H. Shimizu, J. Am. Chem. Soc., 2012, 134, 14338.

58 L. Bellarosa, S. Calero and N. Lopez, Phys. Chem. Chem. Phys., 2012, 14, 7240 .

59 J. H. Cavka, S. Jakobsen, U. Olsbye, N. Guillou, C. Lamberti, S. Bordiga and K. P. Lillerud, J. Am. Chem. Soc., 2008, 130, 13850.

60 J. Ehrenmann, S. K. Henninger and C. Janiak, Eur. J. Inorg. Chem., 2011, 471 .

61 G. Akiyama, R. Matsuda and S. Kitagawa, Chem. Lett., 2010, 39, 360.

62 I. J. Kang, N. A. Khan, E. Haque and S. H. Jhung, Chem. Eur. J., 2011, 17, 6437.

63 K. Tan, N. Nijem, P. Canepa, Q. Gong, J. Li, T. Thonhauser and Y. J. Chabal, Chem. Mater., 2012, 24, 3153.

64 M. De Toni, R. Jonchiere, P. Pullumbi, F.-X. Coudert and A. H. Fuchs, Chemphyschem, 2012, 13, 3497.

65 S. Paranthaman, F.-X. Coudert and A. H. Fuchs, Phys. Chem. Chem. Phys., 2010, 12, 8123.

66 U. Ravon, M. E. Domine, C. Gaudillère, A. Desmartin-Chomel and D. Farrusseng*, New J. Chem., 2008, 32, 937.

67 U. Ravon, M. Savonnet, S. Aguado, M. E. Domine and D. Farrusseng*, Micro-Mesoporous Materials, 2010, 129, 319.

68 J. R. Karra, B. E. Grabicka, Y.-G. Huang and K. S. Walton, J. Colloid Interface Sci., 2013, 392, 331.

69 J. Canivet, J. Bonnefoy, C. Daniel, A. Legrand, B. Coasne and D. Farrusseng, New J. Chem., 2014, DOI: 10.1039/C4NJ00076E

70 W. S. Drisdell, R. Poloni, T. M. McDonald, J. R. Long, B. Smit, J. B. Neaton, D. Prendergast and J. B. Kortright, J. Am. Chem. Soc., 2013, 135, 18183.

71 P. D. C. Dietzel, R. E. Johnsen, R. Blom and H. Fjellvag, Chem. Eur. J., 2008, 14, 2389.

72 F. Bonino, S. Chavan, J. G. Vitillo, E. Groppo, G. Agostini, C. Lamberti, P. D. C. Dietzel, C. Prestipino and S. Bordiga, Chem. Mater., 2008, 20, 4957.

73 K. Schlichte, T. Kratzke and S. Kaskel, Microporous Mesoporous Mater., 2004, 73, 81.

74 M. Haouas, C. Volkringer, T. Loiseau, G. Ferey and F. Taulelle, J. Phys. Chem. C, 2011, 115, 17934.

75 D. J. Tranchemontagne, J. L. Mendoza-Cortes, M. O'Keeffe and O. M. Yaghi, Chem. Soc. Rev., 2009, 38, 1257.

76 A. Vimont, J. M. Goupil, J. C. Lavalley, M. Daturi, S. Surble, C. Serre, F. Millange, G. Ferey and N. Audebrand, J. Am. Chem. Soc., 2006, 128, 3218.

77 L. Grajciar, O. Bludsky and P. Nachtigall, J. Phys. Chem. Lett., 2010, 1, 3354.

78 L. Valenzano, B. Civalleri, S. Chavan, S. Bordiga, M. H. Nilsen, S. Jakobsen, K. P. Lillerud and C. Lamberti, Chem. Mater., 2011, 23, 1700 .
79 A. D. Wiersum, E. Soubeyrand-Lenoir, Q. Yang, B. Moulin, V. Guillerm, M. Ben Yahia, S. Bourrelly, A. Vimont, S. Miller, C. Vagner, M. Daturi, G. Clet, C. Serre, G. Maurin and P. L. Llewellyn, Chem. Asian J., 2011, 6, 3270.

80 G. Wißmann, A. Schaate, S. Lilienthal, I. Bremer, A. M. Schneider and P. Behrens, Microporous Mesoporous Mater., 2012, 152, 64.

81 C. L. McCallum, T. J. Bandosz, S. C. McGrother, E. A. Muller and K. E. Gubbins, Langmuir, 1999, 15, 533.

82 M. Thommes, C. Morlay, R. Ahmad and J. P. Joly, Adsorption, 2011, $17,653$.

83 F. Jeremias, V. Lozan, S. K. Henninger and C. Janiak, Dalton Trans., 2013, 42, 15967.

84 Y. Zhang, Y. Chen, Y. Zhang, H. Cong, B. Fu, S. Wen and S. Ruan, J. Nanopart. Res., 2013, 15, 1.

85 B. Coasne, A. Galarneau, R. J. M. Pellenq and F. Di Renzo, Chem. Soc. Rev., 2013, 42, 4141.

86 B. Coasne, K. E. Gubbins and R. J. M. Pellenq, Adsorption, 2005, 11, 289.

87 S. Brunauer, L. S. Deming, W. E. Deming and E. Teller, J. Am. Chem. Soc., 1940, 62, 1723.

88 F. Rouquerol, J. Rouquerol and K. Sing, Adsorption by Powders and Porous Solids: Principles, Methodology and Applications, Academic Press, 1999.

89 S. Kittaka, S. Ishimaru, M. Kuranishi, T. Matsuda and T. Yamaguchi, Phys. Chem. Chem. Phys., 2006, 8, 3223.

90 G. Akiyama, R. Matsuda, H. Sato, A. Hori, M. Takata and S. Kitagawa, Microporous Mesoporous Mater., 2012, 157, 89.

91 H. Naono, M. Hakuman, T. Tanaka, N. Tamura and K. Nakai, J. Colloid Interface Sci., 2000, 225, 411.

92 M. F. De Lange, J.-J. Gutierrez-Sevillano, S. Hamad, T. J. H. Vlugt, S. Calero, J. Gascon and F. Kapteijn, J. Phys. Chem. C, 2013, 117, 7613.

93 F. Jeremias, A. Khutia, S. K. Henninger and C. Janiak, J. Mater. Chem., 2012, 22, 10148.

94 F. Salles, S. Bourrelly, H. Jobic, T. Devic, V. Guillerm, P. Llewellyn, C. Serre, G. Ferey and G. Maurin, J. Phys. Chem. C, 2011, 115, 10764.

95 V. Haigis, F. X. Coudert, R. Vuilleumier and A. Boutin, Phys. Chem. Chem. Phys., 2013, 15, 19049.

96 P.-A. Albouy and A. Ayral, Chem. Mater., 2002, 14, 3391.

97 D. Jauffrès, C. Yacou, M. Verdier, R. Dendievel and A. Ayral, Microporous Mesoporous Mater., 2011, 140, 120.

98 T. Loiseau, C. Serre, C. Huguenard, G. Fink, F. Taulelle, M. Henry, T. Bataille and G. Ferey, Chem. Eur. J., 2004, 10, 1373.

99 F.-X. Coudert, A. Boutin, A. H. Fuchs and A. V. Neimark, J. Phys. Chem. Lett., 2013, 4, 3198.

100 A. Cheetham, C. Rao and R. Feller, Chem. Commun., 2006, 4780.

101 A. Boutin, D. Bousquet, A. U. Ortiz, F. X. Coudert, A. H. Fuchs, A. Ballandras, G. Weber, I. Bezverkhyy, J. P. Bellat, G. Ortiz, G. Chaplais, J. L. Paillaud, C. Marichal, H. Nouali and J. Patarin, J. Phys. Chem. C, 2013, 117, 8180.

102 F.-X. Coudert, A. U. Ortiz, V. Haigis, D. Bousquet, A. H. Fuchs, A. Ballandras, G. Weber, I. Bezverkhyy, N. Geoffroy, J.-P. Bellat, G. Ortiz, G. Chaplais, J. Patarin and A. Boutin, J. Phys. Chem. C, 2014, 118, 5397.

103 M. Soulard, J. Patarin, V. Eroshenko and R. Regis, in Recent Advances in the Science and Technology of Zeolites and Related Materials eds. E. VanSteen, M. Claeys and L. H. Callanan, 2004, vol. 154, pp. 1830. 
104 J. Liu, Y. Wang, A. I. Benin, P. Jakubczak, R. R. Willis and M. D. LeVan, Langmuir, 2010, 26, 14301.

105 S. K. Henninger, F. Jeremias, H. Kummer and C. Janiak, Eur. J. Inorg. Chem., 2012, 2625.

106 T. Devic, F. Salles, S. Bourrelly, B. Moulin, G. Maurin, P. Horcajada, C. Serre, A. Vimont, J.-C. Lavalley, H. Leclerc, G. Clet, M. Daturi, P. L. Llewellyn, Y. Filinchuk and G. Ferey, J. Mater. Chem., 2012, 22, 10266.

107 P. Horcajada, F. Salles, S. Wuttke, T. Devic, D. Heurtaux, G. Maurin, A. Vimont, M. Daturi, O. David, E. Magnier, N. Stock, Y. Filinchuk, D. Popov, C. Riekel, G. Ferey and C. Serre, J. Am. Chem. Soc., 2011, 133, 17839.

108 G. E. Cmarik, M. Kim, S. M. Cohen and K. S. Walton, Langmuir, 2012, 28, 15606.

109 H. Jasuja, J. Zang, D. S. Sholl and K. S. Walton, J. Phys. Chem. C, 2012, 116, 23526.

110 H. Jasuja and K. S. Walton, J. Phys. Chem. C, 2013, 117, 7062.

$111 \mathrm{M}$. Wickenheisser, F. Jeremias, S. K. Henninger and C. Janiak, Inorg. Chim. Acta, 2013, 407, 145.

112 H. Reinsch, M. A. van der Veen, B. Gil, B. Marszalek, T. Verbiest, D. de Vos and N. Stock, Chem. Mater., 2013, 25, 17.

113 J. C. Saint Remi, T. Remy, V. Van Hunskerken, S. van de Perre, T. Duerinck, M. Maes, D. De Vos, E. Gobechiya, C. E. A. Kirschhock, G. V. Baron and J. F. M. Denayer, Chemsuschem, 2011, 4, 1074.

114 R. P. Lively, M. E. Dose, J. A. Thompson, B. A. McCool, R. R. Chance and W. J. Koros, Chem. Commun., 2011, 47, 8667.

115 A. U. Ortiz, A. P. Freitas, A. Boutin, A. H. Fuchs and F.-X. Coudert, Phys. Chem. Chem. Phys., 2014, 16, 9940.

116 S. Aguado, J. Canivet and D. Farrusseng, J. Mater. Chem., 2011, 21, 7582.

117 K. Zhang, R. P. Lively, M. E. Dose, A. J. Brown, C. Zhang, J. Chung, S. Nair, W. J. Koros and R. R. Chance, Chem. Commun, 2013, 49, 3245.

118 D. Fairen-Jimenez, R. Galvelis, A. Torrisi, A. D. Gellan, M. T. Wharmby, P. A. Wright, C. Mellot-Draznieks and T. Dueren, Dalton Trans., 2012, 41, 10752.

119 D. Fairen-Jimenez, S. A. Moggach, M. T. Wharmby, P. A. Wright, S. Parsons and T. Dueren, J. Am. Chem. Soc., 2011, 133, 8900.

120 S. Aguado, G. Bergeret, M. P. Titus, V. Moizan, C. Nieto-Draghi, N. Bats and D. Farrusseng, New J. Chem., 2011, 35, 546.

121 G. Ortiz, H. Nouali, C. Marichal, G. Chaplais and J. Patarin, Phys. Chem. Chem. Phys., 2013, 15, 4888.

122 B. Lefevre, A. Saugey, J. L. Barrat, L. Bocquet, E. Charlaix, P. F. Gobin and G. Vigier, J. Chem. Phys., 2004, 120, 4927.

123 B. Coasne, A. Galarneau, F. Di Renzo and R. J. M. Pellenq, J. Phys. Chem. C, 2009, 113, 1953.

124 J. C. Tan, B. Civalleri, C. C. Lin, L. Valenzano, R. Galvelis, P. F. Chen, T. D. Bennett, C. Mellot-Draznieks, C. M. Zicovich-Wilson and A. K. Cheetham, Phys. Rev. Lett., 2012, 108.

125 C. R. Wade, T. Corrales-Sanchez, T. C. Narayan and M. Dinca, Energy Environ. Sci., 2013, 6, 2172.

126 C. Hansch, A. Leo, S. H. Unger, K. H. Kim, D. Nikaitani and E. J. Lien, J. Med. Chem, 1973, 16, 1207.

127 S. Horike, S. Shimomura and S. Kitagawa, Nature Chem., 2009, 1, 695.
128 N. A. Ramsahye, T. Thuy Khuong, L. Scott, F. Nouar, T. Devic, P. Horcajada, E. Magnier, O. David, C. Serre and P. Trens, Chem. Mater., 2013, 25, 479.

129 R. Kitaura, F. Iwahori, R. Matsuda, S. Kitagawa, Y. Kubota, M. Takata and T. C. Kobayashi, Inorg. Chem., 2004, 43, 6522.

130 A. Shigematsu, T. Yamada and H. Kitagawa, J. Am. Chem. Soc., 2011, 133, 2034.

131 T. Lescouet, E. Kockrick, G. Bergeret, M. Pera-Titus, S. Aguado and D. Farrusseng, J. Mater. Chem., 2012, 22, 10287.

132 T. Lescouet, E. Kockrick, G. Bergeret, M. Pera-Titus and D. Farrusseng, Dalton Trans., 2011, 40, 11359.

133 G. Chaplais, A. Simon-Masseron, F. Porcher, C. Lecomte, D. BazerBachi, N. Bats and J. Patarina, Phys. Chem. Chem. Phys., 2009, 11, 5241.

134 C. Volkringer, T. Loiseau, N. Guillou, G. Ferey, E. Elkaim and A. Vimont, Dalton Trans., 2009, 2241.

135 A. U. Ortiz, A. Boutin and F.-X. Coudert, Chem. Commun., 2014, 50, 5867.

136 T. Fukushima, S. Horike, Y. Inubushi, K. Nakagawa, Y. Kubota, M. Takata and S. Kitagawa, Angew. Chem. Int. Ed., 2010, 49, 4820

137 M. Gaab, N. Trukhan, S. Maurer, R. Gummaraju and U. Müller, Microporous Mesoporous Mater., 2012, 157, 131.

138 A. Khutia, H. U. Rammelberg, T. Schmidt, S. Henninger and C. Janiak, Chem. Mater., 2013, 25, 790.

139 H. Reinsch, B. Marszalek, J. Wack, J. Senker, B. Gil and N. Stock, Chem. Commun., 2012, 48, 9486.

140 J. Deng, R. Z. Wang and G. Y. Han, Prog. Energ. Combust. Sci., 2011, 37, 172.

141 F. Meunier, Appl. Therm. Eng., 2013, 61, 830.

142 Y. I. Aristov, Int. J. Refrig., 2009, 32, 675.

143 S. K. Henninger, H. A. Habib and C. Janiak, J. Am. Chem. Soc., 2009, 131, 2776.

144 J.-P. Zhang, A.-X. Zhu, R.-B. Lin, X.-L. Qi and X.-M. Chen, $A d v$. Mater., 2011, 23, 1268.

145 W. M. Raldow and W. E. Wentworth, Sol. Energy, 1979, 23, 75.

146 Y. I. Aristov, Appl. Therm. Eng., 2013, 50, 1610.

147 Y. I. Aristov, Appl. Therm. Eng., 2012, 42, 18.

148 J.-H. Wee, Renew. Sust. Energ. Rev., 2007, 11, 1720.

149 S. G. Kandlikar and Z. Lu, J. Fuel Cell Sci. Tech., 2009, 6, 044001.

150 T. Yamada, Y. Shirai and H. Kitagawa, Chem. Asian J., 2014, 9, 1316.

151 K.-D. Kreuer, S. J. Paddison, E. Spohr and M. Schuster, Chem. Rev., 2004, 104, 4637.

152 K.-D. Kreuer, A. Rabenau and W. Weppner, Angew. Chem. Int. Ed., 1982, 21, 208.

153 K.-D. Kreuer, Chem. Mater., 1996, 8, 610.

154 J. T. S. Irvine, D. C. Sinclair and A. R. West, Adv. Mater., 1990, 2 , 132.

155 S. Kanda, K. Yamashita and K. Ohkawa, Bull. Chem. Soc. Jpn., 1979, 52, 3296.

156 M. Yoon, K. Suh, S. Natarajan and K. Kim, Angew. Chem. Int. Ed., 2013, 52, 2688.

157 Y. Ren, G. H. Chia and Z. Gao, Nano Today, 2013, 8, 577.

158 A. Morozan and F. Jaouen, Energy Environ. Sci., 2012, 5, 9269.

159 A. Mallick, T. Kundu and R. Banerjee, Chem. Commun., 2012, 48, 8829. 
160 S. C. Sahoo, T. Kundu and R. Banerjee, J. Am. Chem. Soc., 2011, 133, 17950 .

161 M. G. Goesten, J. Juan-Alcañiz, E. V. Ramos-Fernandez, K. B. Sai Sankar Gupta, E. Stavitski, H. van Bekkum, J. Gascon and F. Kapteijn, J. Catal., 2011, 281, 177.

162 J. M. Taylor, R. K. Mah, I. L. Moudrakovski, C. I. Ratcliffe, R. Vaidhyanathan and G. K. H. Shimizu, J. Am. Chem. Soc., 2010, 132, 14055.

163 S. Kim, K. W. Dawson, B. S. Gelfand, J. M. Taylor and G. K. H. Shimizu, J. Am. Chem. Soc., 2013, 135, 963.

164 J. M. Taylor, K. W. Dawson and G. K. H. Shimizu, J. Am. Chem. Soc., 2013, 135, 1193.

165 R. M. P. Colodrero, P. Olivera-Pastor, E. R. Losilla, M. A. G. Aranda, L. Leon-Reina, M. Papadaki, A. C. McKinlay, R. E. Morris, K. D. Demadis and A. Cabeza, Dalton Trans., 2012, 41, 4045.

166 R. M. P. Colodrero, P. Olivera-Pastor, E. R. Losilla, D. HernándezAlonso, M. A. G. Aranda, L. Leon-Reina, J. Rius, K. D. Demadis, B. Moreau, D. Villemin, M. Palomino, F. Rey and A. Cabeza, Inorg. Chem., 2012, 51, 7689.

167 F. Costantino, A. Donnadio and M. Casciola, Inorg. Chem., 2012, 51, 6992.

168 E. Pardo, C. Train, G. Gontard, K. Boubekeur, O. Fabelo, H. Liu, B. Dkhil, F. Lloret, K. Nakagawa, H. Tokoro, S.-i. Ohkoshi and M. Verdaguer, J. Am. Chem. Soc., 2011, 133, 15328.

169 M. Sadakiyo, T. Yamada and H. Kitagawa, J. Am. Chem. Soc., 2009, 131, 9906.

170 S. Horike, D. Umeyama, M. Inukai, T. Itakura and S. Kitagawa, J. Am. Chem. Soc., 2012, 134, 7612.

171 S. Sen, N. N. Nair, T. Yamada, H. Kitagawa and P. K. Bharadwaj, J. Am. Chem. Soc., 2012, 134, 19432.

172 S. Horike, Y. Kamitsubo, M. Inukai, T. Fukushima, D. Umeyama, T. Itakura and S. Kitagawa, J. Am. Chem. Soc., 2013, 135, 4612.

173 G. Xu, K. Otsubo, T. Yamada, S. Sakaida and H. Kitagawa, J. Am. Chem. Soc., 2013, 135, 7438.

174 X. Liang, F. Zhang, W. Feng, X. Zou, C. Zhao, H. Na, C. Liu, F. Sun and G. Zhu, Chem. Sci., 2013, 4, 983.

175 B. Wu, X. Lin, L. Ge, L. Wu and T. Xu, Chem. Commun., 2013, 49, 143.

176 A. A. Argun, J. N. Ashcraft and P. T. Hammond, Adv. Mater., 2008, 20, 1539 . 